\title{
6. DIE RUHE VOR DEM STURM
}

\subsection{Deutschland unterm Hakenkreuz}

André François-Pōncet änderte - wie gesehen - zwischen dem Herbst 1934 und dem Frühjahr 1935 Ziel, Mittel und Motiv seiner Deutschlandpolitik. Die Frage ist, ob dieser Wandel in den deutschlandpolitischen Vorstellungen des Botschafters durch die innere Entwicklung des Reiches nach dem RöhmPutsch und dem Tod von Hindenburgs beschleunigt worden ist. André François-Poncet sah im Herbst 1934 das Reich mit vier Problemen konfrontiert: einem politischen, einem sozialen, einem religiösen und einem wirtschaftlichfinanziellen ${ }^{1}$. Das Hauptproblem schienen dem Botschafter nicht die Konflikte in der Partei, nicht die betriebsinternen Konfrontationen zwischen Arbeitnehmern und -gebern und auch nicht der Konflikt mit der Evangelischen Kirche, sondern die kritische Wirtschafts- und Finanzlage Deutschlands zu sein, die die Reichsregierung zwingen werde, »une réglementation sévère« einzuführen, wenn nicht für Grundnahrungsmittel, so doch für Fett und Baumwolle, Metalle und Kautschuk. Insofern glaubte André François-Poncet den deutschen Beteuerungen nicht, daß das Reich die Schwierigkeiten überwunden habe ${ }^{2}$. Im Gegenteil:

L'année 1935 les trouvera plus aiguës et plus pressantes que l'année écoulée. La crise économique et financière avec laquelle l'Allemagne est aux prises ne paraît pas en décroissance. Les rivalités de personnes et d'intérêts, la diversité et l'opposition des courants que recouvre d'un voile trompeur le mot de national-socialisme continuent d'affaiblir le gouvernement et de compliquer sa tâche. Entre la Reichswehr, porte-parole des milieux industriels et conservateurs et les SS, qui prétendent constituer la troupe d'élite du III Reich [...], subsiste un conflit que le silence imposé à la presse ne parvient pas à dissimuler à l'opinion ${ }^{3}$.

Trotz der zunehmenden Schwierigkeiten wagte der Botschafter keine Prognose über die Zukunft des Reiches. Vielmehr warnte André François-Poncet vor Gerüchten, die »de graves événements allant jusqu'à mettre en péril le régime hitlérien « nach der Volksabstimmung im Saarland vorhersagten ${ }^{4}$. Sie enthielten durchaus einen wahren Kern, der aber vergrößert und verformt

1 Zur innenpolitischen Entwicklung siehe HILDEBRAND, Drittes Reich, S.10ff. und S. 43ff.

2 Depesche Nr. 1465 vom 17. Oktober 1934 (Botschafter François-Poncet an Außenminister Laval), in: DDF VIV/1, Nr. 487, S. 778-787, hier insbesondere S. 779-783.

3 Depesche Nr. 1784 vom 12. Dezember 1934 (Botschafter François-Poncet an Außenminister Laval), in: DDF VIII/1, Nr. 242, S. 363-367, hier S. 366.

4 Depesche Nr. 1849 vom 26. Dezember 1934 (Botschafter François-Poncet an Außenminister Laval), S. 1f., in: CADN, Ambassade Berlin, Carton 197. 
werde. Der Botschafter glaubte nicht, daß sich die Unzufriedenheit der SA und der SS in einem Aufstand entladen könnte, weil den Verbänden die entsprechenden Führer fehlten und sie mit dem Widerstand der Reichswehr rechnen müßten. Daß die Reichswehr die Initiative ergreifen, eine »Säuberung « durchführen könne, weil sie das Regime »normalisieren«, »moralisieren« und in Richtung auf einen gemäßigten Konservativismus, ja zur Rückkehr der Monarchie bewegen möchte, glaubte der Botschafter ebenfalls nicht. »La Reichswehr a bien«, gestand André François-Poncet zu, "ces préoccupations; et même il est vraisemblable que son haut commandement est demeuré, au fond du cœur, monarchiste, et songe à frayer les voies au retour de la monarchie ${ }^{5}$. Bis auf den letzten Punkt schienen sich die Reichswehrführung und der "Führer« einig zu sein. »Hitler est lui-même résolu à normaliser et à moraliser le régime. Il veut l'épurer ${ }^{6}$. Diese »Säuberung « laufe täglich im geheimen ab. Wie sie sich entwickeln werde, das schien dem Botschafter angesichts der Persönlichkeit des Reichskanzlers unvorhersehbar ${ }^{7}$. Die Reichswehr stehe ihm jedenfalls mit General von Blomberg fest zur Seite, weil sie von Hitler die größten Zugeständnisse bekommen habe. »Il est, pour elle«, hielt der Botschafter fest, »le chef de Gouvernement le plus commode. Depuis qu'il est au pouvoir, elle a réalisé, notamment en matière de réarmement tout ce qu'elle souhaitait. Elle ne le lâchera pas sans de puissants motifs. Il est encore pour elle précieux fétiche. Entre elle et lui l'accord pour le moment est étroit. Il n'y a pas de conflit grave entre Hitler et la Reichswehr ${ }^{8}$. Ob das immer so bleiben werde, sei nicht die Frage. Fraglich sei vielmehr, ob Hitler bereit ist, so weit zu gehen, wie ihn die Reichswehr zu drängen versucht.". Sicher schien, $\mathrm{da} ß$ die Reichswehr die bewaffneten SS-Einheiten kontrollieren und führen wolle, daß sie den Antisemitismus und die religiöse Verfolgung »tadele«, da $B$ sie Goebbels feindlich gesinnt sei und Rosenberg verabscheue. "Hitler l'écoutera-t-il? La suivra-t-il? Lui résistera-t-il? Et que se passera-t-il, alors? ${ }^{10}$. Das könne keiner vorhersagen, die Stunde der Krise habe noch nicht geschlagen. $\mathrm{Da} ß$ die wirtschaftliche und finanzielle Situation dem $» D r i t t e n$ Reich « ein Ende bereiten werde, glaubte André François-Poncet nicht. »Il est manifeste«, gestand der Botschafter $\mathrm{zu}$, »que la situation économique et financière de l'Allemagne n'est pas brillante ${ }^{11}$. Gleichwohl drohten keine kurzfristigen Gefahren, stehe keine Katastrophe bevor. Deshalb warnte André

Ibid. S. 3.

Ibid.

7 Ibid. S. 3f.

8 Ibid. S. 4.

9 Ibid.

10 Ibid.

11 Ibid. S. 5. 
François-Poncet davor, die französische Politik auf einem baldigen Sturz der Nationalsozialisten aufzubauen: "Spéculer sur une catastrophe imminente du $3^{\mathrm{e}}$ Reich est, à tous les égards, une spéculation imprudente; donner à Hitler la possibilité de rassembler et d'exciter contre la France le sentiment national de l'Allemagne, n'est pas nécessairement lui nuire; c'est, peut-être, au contraire, le servir « ${ }^{12}$.

Die kritische Einschätzung der wirtschaftlichen und finanziellen Lage des Reiches und seiner Zukunftsaussichten behielt der französische Botschafter mindestens bis zum Frühjahr 1937 bei $^{13}$. Deutschland leide zwar an einem extremen Devisen- und Rohstoffmangel, einer Lohn- und Preiskrise und einer galoppierenden Inflation, müsse aber nicht kurzfristig mit Gefahren rechnen, wiederholte André François-Poncet im Sommer 1935 seine Ansicht ${ }^{14}$. »'Allemagne est engagée sur une mauvaise pente«, schrieb er bei dieser Gelegenheit. »Elle n'est pas en bas de cette pente. Elle y glisse lentement «. Diese Rutschpartie könne noch lange dauern, prophezeite der Botschafter im Sommer 1935. "Il faut se garder de sous-estimer les ressources d'un aussi énorme pays, comme, d'ailleurs, les résultats que peut obtenir un régime de dictature, décidé à ne reculer devant rien; la contrainte produit tous les effets de la confiance $\ll$. Erst nach einer politischen oder militärischen Katastrophe werde die deutsche Volkswirtschaft auf einen Schlag zusammenbrechen. "D'ici là, elle est capable de résister au-delà des prévisions normales. En tous cas, à l'heure qu'il est, un effondrement ne paraît pas imminent «. Außerdem würden ökonomische oder finanzielle Gründe dem Regime kein Ende bereiten. Diese Schwierigkeiten könnten das Reich auf diametral entgegengesetzte Wege führen. »Elles peuvent inciter le Reich à vouloir la paix et à chercher, dans la paix, des crédits étrangers qui lui permettraient de respirer; et c'est peut-être ce qui explique l'attitude de $\mathrm{M}$. Hitler à l'égard de l'Angleterre. Mais, ces mêmes difficultés, si elles devaient s'aggraver et se révéler sans remède, pourraient aussi bien inciter le national-socialisme à chercher une issue dans la guerre ${ }^{15}$. Soweit waren die deutschen Kriegsvorbereitungen aber noch nicht. Daß das nationalsozialistische Regime aufgrund von wirtschaftlichen und finanziellen Schwierigkeiten im Winter 1935/1936 gestürzt werden könnte, schien dem Botschafter Ende 1935 immer noch unwahr-

12 Ibid. S. 7.

${ }^{13}$ Im Gegensatz zu André François-Poncet bezeichnet die historische Forschung unter innenpolitischen Gesichtspunkten die Jahre zwischen 1935 und 1938 als Periode der »Konsolidierung « der nationalsozialistischen Herrschaft, ja spricht sogar von einem »NSWirtschaftswunder«, vgl. Norbert FREI, Der Führerstaat. Nationalsozialistische Herrschaft 1933 bis 1945, München ${ }^{2} 1989$, S. $85 \mathrm{ff}$.

14 Depesche Nr. 939 vom 3. Juli 1935 (Botschafter François-Poncet an Ministerpräsident und AuBenminister Laval), S. 6ff., in: CADN, Ambassade Berlin, Série B, Carton 204.

15 Ibid. S. 10. 
scheinlich ${ }^{16}$. Vielmehr schienen dem Botschafter die wirtschaftlichen Schwierigkeiten und die zunehmenden Versorgungsmängel mäßigend auf die nationalsozialistische Führung zu wirken. Gleichwohl schloß André FrançoisPoncet nach wie vor die Möglichkeit nicht aus, daß die Reichsregierung die Flucht in einen Krieg antreten könnte ${ }^{17}$. Dieser Gedanke wurde durch den "militärischen Charakter« des 4-Jahres-Planes gestützt, der im Frieden eine Kriegswirtschaft etabliert ${ }^{18}$.

Daß die Reichsregierung auf einen Krieg zusteuere, schien André FrançoisPoncet nicht nur die Wirtschafts- und die Außenpolitik zu belegen. Das bestätigte in seinen Augen auch die Selbstdarstellung des Reiches, die der Botschafter am Beispiel der Nürnberger Reichsparteitage beschrieb und beurteilte $^{19}$. Hatte der »Parteitag des Sieges « vom 31. August bis 3. September 1933 noch »le caractère d'une énorme démonstration de propagande ${ }^{20}$, schien André François-Poncet das »spectacle militaire« einer der »traits caractéristiques « des "Parteitags des Willens « vom 4. bis 10. September 1934 gewesen zu sein: "L'an dernier l'armée régulière n'avait pas figuré au Congrès. Cette année, elle y a été représentée non seulement par des soldats, mais aussi par ses officiers généraux les plus importants; elle y a occupé une place d'honneur; elle y est apparue en conclusion des événements du 30 juin et de l'évélation du Führer à la première magistrature de l'État comme la tutrice sinon la maitresse du régime ${ }^{21}$. Der $»$ Reichsparteitag der Freiheit« schien in den Augen des Botschafters im Herbst 1935 die letzten Zweifel über die Absichten Hitler-Deutschlands auszuräumen: "L'emblème du Troisième Reich est le glaive«, schrieb André François-Poncet in einer 40seitigen Analyse $^{22}$. Der Nationalsozialismus habe die Militarisierung des Reiches viel weiter getrieben als das wilhelminische Deutschland. "Qu'il porte sur l'épaule la bêche du Service de Travail ou le fusil de la jeune recrue ou qu'il manie les outils de l'artisan, le citoyen du Troisième Reich ne cesse jamais d'être soldat, ni d'être soumis à des formes de vie et à un entraînement d'allures militaires.

${ }^{16}$ Depesche Nr. 1596 vom 5. November 1935 (Botschafter François-Poncet an Ministerpräsident und Außenminister Laval), in: DDF XIII/1, Nr. 169, S. 238f., hier S. 238.

17 Depesche Nr. 1515 vom 14. Oktober 1936 (Botschafter François-Poncet an Außenminister Delbos), in: DDF IIL/2, Nr. 351, S. 528-535, insbesondere S. 531ff., Zitat S. 533.

18 Depesche Nr. 1599 vom 28. Oktober 1936 (Botschafter François-Poncet an Außenminister Delbos), in: DDF III/2, Nr. 417, S. 642-648.

19 André François-Poncet beehrte erst 1937 und 1938 die Reichsparteitage mit seiner Anwesenheit. 1933 bis 1936 verfolgte sie der Botschafter mit größter Aufmerksamkeit, wie seine ausführliche Berichterstattung zeigt.

${ }^{20}$ Vgl. Telegramme Nr. 1559-1562 vom 4. September 1933, in: DDF IV/1, Nr. 172, S. $292 f$.

21 Telegramme Nr. 1728-1731 vom 10. September 1934, in: DDF VII1, Nr. 291, S. $429 f$.

22 Depesche Nr. 1344 vom 18. September 1935 (Botschafter François-Poncet an Ministerpräsident und Außenminister Laval), in: CADN, Ambassade Berlin, Série B, Carton 202. 
C'est vers la défense nationale qu'est orientée toute l'énergie du pays « ${ }^{23}$. Ziel sei, ein Volk als Armee zu organisieren. Das schien dem Botschafter keine gute Aussicht zu sein, zumal sich der Reichskanzler auf die Seite der Extremisten in der Partei geschlagen habe ${ }^{24}$. Unter der Führung dieses Mannes bleibe die Entwicklung des Reiches - trotz der Friedensversicherungen des »Führers $\ll$ - ein alarmierendes Thema. »Depuis le 30 juin $1934 \ll$, schrieb er im Herbst 1935, »le régime se normalisait. Aujourd'hui, il redevient anormal; il rebondit; il écume; il réclame des victimes«. Juden ${ }^{25}$, Russen und Reaktionäre werden ihm als potentielle Opfer angeboten. »Mais après?«, fragte sich der Botschafter besorgt. »Tout ce fanatisme ne se repaître pas de vent. Quand le Minotaure aura dévoré tous les ennemis intérieurs, quand il n'aura plus rien à se mettre sous la dent, comment se comportera-t-il? Quand il aura épuisé toutes les possibilités de diversion intérieure, ne recherchera-t-il pas les diversions extérieures? ${ }^{26}$ «. Insofern sei das zu Beginn des Parteitages übergebene Reichsschwert kein beruhigendes Zeichen, zumal sich - wie gesehen - dem Botschafter die Analogien zwischen der Politik von Hitler und Wilhelm II. immer mehr aufdrängten.

[E]lle procède par ruse, par corruption, par menace, par machination et par coups de théâtre. Elle se flatte des mêmes espérances, et aussi des mêmes illusions. Elle croit qu'on peut entretenir une armée écrasante sans susciter des coalitions défensives. Elle fait fond sur la neutralité de l'Angleterre, sur les divisions intestines de la France, sur l'inertie et sur la lâcheté des Russes. Quoiqu'elle s'en défende, elle prépare en secret le bouleversement de la carte de l'Europe ${ }^{27}$.

Angesichts der ihm deutlich vor Augen tretenden Parallelen zwischen »Zweitem « und »Drittem Reich«, zwischen Kaiser und »Führer« fürchtete André François-Poncet, daß die gleichen Ursachen die gleichen Folgen zeitigen müßten ${ }^{28}$. Diese Furcht konnten selbst die das friedliche Deutschland zur Schau stellenden Olympischen Spiele nicht vertreiben ${ }^{29}$. Die wirtschaftlichen

Die in Nürnberg verabschiedeten »Rassengesetze« erschienen André François-Poncet als ein "instrument d'oppression redoutable«, mit dem »sur l'ensemble de la nation une véritable tyrannie« ausgeübt werden könne, siehe Depesche Nr. 1344 vom 18. September 1935 (Botschafter François-Poncet an Ministerpräsident und Außenminister Laval), S. 16f., in: CADN, Ambassade Berlin, Série B, Carton 202. Der Botschafter sah in den Gesetzen zwar die Rechtsbeschränkung für die Deutschen jüdischen Bekenntnisses, aber auch eine vermeintliche Rechtssicherheit für sie, siehe ibid. S. 18.

${ }^{28}$ Telegramme Nr. 773-778 vom 11. März 1936, in: CADN, Ambassade Berlin, Série B, Carton 140.

29 Vgl. Telegramme Nr. 2382-2387 vom 2. August 1936 (Botschafter François-Poncet an AuBenminister Delbos), in: DDF IIU/2, Nr. 61 und Telegramme Nr. 2611-2613 vom 
und finanziellen Schwierigkeiten wirkten nämlich auch nicht mehr mäßigend auf die Reichsführung, weil sie sich immer mehr innenpolitisch bemerkbar machten. »L'année 1936 s'achève donc dans une atmosphère de malaise à l'intérieur «, schrieb André François-Poncet Ende $1936^{30}$. Vor diesem Hintergrund drängten Außenminister von Neurath und Wirtschaftsminister Schacht im Frühjahr 1937 auf eine Weiterentwicklung des Regimes, die Deutschland an die westlichen Staaten annähern und in den Kreis der Großmächte zurückbringen sollte ${ }^{31}$. André François-Poncet bestätigte im Sommer 1937 Berichte, die eine $»$ Normalisierung « und $» B e s a ̈ n f t i g u n g$ « des Regimes vorhersagten ${ }^{32}$. Insbesondere Wirtschaftsminister Schacht suchte nach Möglichkeiten, die wirtschaftliche Lage des Reiches zu verbessern. Eine Suche, die - wie zu zeigen sein wird - in den Augen des Botschafters den Weg eröffnete, über einen kolonialen Ausgleich eine deutsch-französische Annäherung, ja eine europäische Gesamtregelung zu suchen. Diese von François-Poncet sofort ergriffene Möglichkeit bestand aber nur kurze Zeit. Reichskanzler Hitler machte sie mit seiner Schlußansprache auf dem Reichsparteitag $1937 \mathrm{zu}$ nichte: »Ses déclarations ne permettent guère d'entrevoir que nous nous approchions d'une ère de détente et de concorde; elles semblent plutôt présager que nous connaîtrons encore bien des jours tourmentés « ${ }^{33}$. Diese Aussicht schien dem Botschafter unter einer, schon bekannten, Bedingung nicht weiter tragisch:

Si l'Allemagne hitlérienne a le sentiment qu'elle rencontrera en face d'elle un bloc redoutable, elle sera bien obligée d'adoucir ses angles, d'atténuer ses prétentions et de composer avec les forces disposées à faire obstacle à ses exigences. L'avenir dépendra, dans une large mesure, de la fermeté et de l'union des Pays pour lesquels l'impérialisme idéologique du Troisième Reich constitue une menace commune. Il dépendra, en premier lieu, de la solidité de l'entente franco-anglaise ${ }^{34}$.

Ob die französisch-britische Entente der stïrmischen Zukunft standhalten wird, ist im folgenden am Beispiel der Rheinland-Besetzung und der Krisen um die Tschechoslowakei zu untersuchen.

18. August 1936 (Botschafter François-Poncet an Außenminister Delbos), in: CADN, Ambassade Berlin, Série B, Carton 142.

30 Depesche Nr. 1879 vom 31. Dezember 1936 (Botschafter François-Poncet an Außenminister Delbos), in: DDF IV/2, Nr. 233, S. 385-395, insbesondere S. 392f., Zitat S. 395.

31 Telegramm Nr. 1655 vom 22. April 1937 (Botschafter François-Poncet an Außenminister Delbos), in: DDF VI/2, Nr. 317, S. 517f.

32 Siehe die Note des Botschafters François-Poncet an Außenminister Delbos vom 17. Juni 1937, in: AMAE/Papiers 1940, Papiers Delbos, Cabinet du Ministre, Vol. 1, S. 225-265, hier S. 264.

33 Depesche Nr. 1447 vom 16. September 1937 (Botschafter François-Poncet an Außenminister Delbos), in: CADN, Ambassade Berlin, Série B, Carton 209.

34 Ibid. S. 24. 


\subsection{Die Remilitarisierung des Rheinlandes}

»Rien de neuf« brachte nach Einschätzung André François-Poncets die Rede des Reichskanzlers am 21. Mai $1935^{35}$. Hitler habe zu den zur Verhandlung anstehenden Paktvorschlägen die bekannten Positionen Deutschlands vertreten, ohne sich den unterbreiteten Angeboten anzunähern. Den französischsowjetischen Vertrag habe er Frankreich angekreidet, dem der Reichskanzler gleichwohl eine Annäherung, ja die »Freundschaft« angeboten habe. Allerdings werfe die erste Hälfte der Rede einen Schatten auf die zweite.

Si le Chancelier aime tant la paix et souhaite si vivement la conciliation était-il opportun qu'il donnât un ton si âpre et parfois si insolent à son argumentation? Etait-il convenable de mêler aux avances adressées par lui à la France des promesses seulement conditionnelles de respecter à l'avenir les accords de Locarno accompagnées d'un avertissement désagréable au sujet de la zone démilitarisée? Etait-il nécessaire de parler de la Russie et de la Lithuanie, en des termes qui paraissent indiquer le point de l'horizon d'où risquait venir la prochaine guerre? ${ }^{36}$.

Sicher seien die 13 Punkte nicht ohne Wert. Die durch die Wiedereinführung der Wehrpflicht in Deutschland unterbrochenen Gespräche müßten aber von den Westmächten wieder aufgenommen werden; Deutschland werde - nach der Rede Hitlers - nicht die Initiative ergreifen ${ }^{37}$. André François-Poncet ging auf diese Aufforderung nicht ein; er war - wie gesehen - nach der Wiedereinführung der Wehrpflicht von seiner Annäherungs- und Verständigungspolitik abgerückt. Infolgedessen fuhr der Botschafter - ohne weiteren Kommentar einen Tag nach der Rede für einen Monat in Urlaub ${ }^{38}$.

Die Abwendung von einer kooperativen Deutschlandpolitik hatte aber nicht lange Bestand. Mitte November 1935 griff der Botschafter - aus Gründen, die im folgenden darzustellen sein werden - die von Reichskanzler Hitler unterbreiteten Verhandlungsvorschläge in einem »schéma« für den französischen

Telegramme Nr. 1287-1302 vom 22. Mai 1935, S. 3ff., in: CADN, Ambassade Berlin, Série B, Carton 136. Text der "außenpolitischen Erklärung des Reichskanzlers« vor dem Reichstag siehe Schulthess' Europäischer Geschichtskalender 1935, S. 99-124.

36 Telegramme Nr. 1306-1313 vom 22. Mai 1935, in: DDF X/1, Nr. 434, S. 652-654, hier S. 653.

${ }^{37}$ Ibid.

38 Siehe Telegramm Nr. 1321 vom 22. Mai 1935, in: CADN, Ambassade Berlin, Série B, Carton 136. Auf der Durchreise in Paris lieferte André François-Poncet zwar im französischen Außenministerium eine verbesserte, fehlerfreie Übersetzung des Schlußteils der Rede mit den 13 Punkten ab, ausführliche Gespräche scheint er aber am Quai d'Orsay nicht geführt zu haben. Jedenfalls finden sich in den Quellen keine Belege. Der Botschafter kehrte am 22. Juni wieder nach Berlin zurück, siehe Telegramm Nr. 1587 vom 22. Juni 1935, in: CADN, Ambassade Berlin, Série B, Carton 136. 
Ministerpräsidenten auf ${ }^{39}$. Die Rede vom 21. Mai 1935 schien André François-Poncet inzwischen eine Reihe von Anknüpfungspunkten zu enthalten, die für eine Wiederaufnahme der unterbrochenen Paktverhandlungen sprächen. Die sollten, so die modifizierte Ansicht André François-Poncets, von der französischen Außenpolitik vorangetrieben werden. Der Botschafter kehrte mit dem »schéma« zur Politik der kollektiven Sicherheit zurück, die er mit seinen vor Stresa geäußerten Forderungen - wie oben gesehen - verlassen hatte. Er schwenkte mithin auf die von Pierre Laval vertretene Linie der französischen Außenpolitik ein $^{40}$. Ziel sei, über die kollektive Sicherheit Europas die individuelle Sicherheit jedes Staates zu organisieren. So hoffte André François-Poncet die Bildung zweier antagonistischer Lager zu verhindern und eine »europäische Union« zu schaffen. Der gute Wille Frankreichs und - so ist zwischen den Zeilen zu lesen - der des Botschafters würde nicht fehlen. Die Gründe für den Einstellungswandel André François-Poncets sind in drei Entwicklungen zu suchen, die die Grundlagen für die französische Außenpolitik so veränderten, daß der vom französischen Botschafter geforderte Konfrontationspolitik die Basis entzogen worden war. Nicht nur zeitlich, sondern auch inhaltlich, steht, jedenfalls nach Ansicht André FrançoisPoncets, das deutsch-britische Flottenabkommen an erster Stelle, dessen Vorbereitung und $A b s c h l u B$ der französische Botschafter nicht auf seinem Posten in Berlin verfolgte ${ }^{41}$. André François-Poncet reagierte erst nach seinem Urlaub Ende Juni auf die grundlegend veränderte Situation. Ende Mai - als der Botschafter in den Urlaub aufbrach - stand Deutschland unter dem Eindruck der Konferenz von Stresa und der Resolution von Genf: „Elle en était consternée«, notierte André François-Poncet Ende Juni rückblickend ${ }^{42}$. Vor Deutschland hatte sich eine "Front« gebildet, die das Land zum Eintritt in die Politik der kollektiven Sicherheit verpflichten oder isolieren wollte. Der französisch-sowjetische Vertrag habe in Deutschland den Eindruck der Einkreisung, das Gefühl der Ohnmacht und das Bewußtsein einer Niederlage gesteigert $^{43}$. Nach seiner Rückkehr war die Atmosphäre anders: Das deutschbritische Flottenabkommen habe die Wolken über dem Reich vertrieben, dem die Sonne wieder lache. Europe drohte sich ohne bzw. gegen Deutschland zu organisieren. Diese Gefahr scheint vorüber zu sein. Daß Deutschland die Gunst der Stunde nicht gegen Frankreich ausnutze, sondern die Zeit für ein

39 Siehe Anhang, Dokument Nr. 6: »Le but que poursuit la politique française«, S. 341-343.

${ }^{40}$ Zur »politique mouvante « Lavals siehe Fred KUPFERMAN, Pierre Laval diplomate, in: Politique Étrangère 51 (1986) S. 57-66, hier S. 62. Viel kritischer schon DURosELLE, Décadance, S. 123ff. Klarsichtig RÉMOND, Siècle, S. 160.

41 Zum Hintergrund siehe HILDEBRAND, Vergangenes Reich, S. 696ff.

42 Depesche Nr. 916 vom 28. Juni 1935 (Botschafter François-Poncet an Ministerpräsident und Außenminister Laval), in: DDF XI/1, Nr. 175, S. 274-278, hier S. 274.

43 Ibid. Zum Hintergrund siehe DUROSELLE, Histoire diplomatique, S. $183 \mathrm{f}$. 
Abkommen mit Frankreich gekommen halte, machte André François-Poncet mißtrauisch. Gleichzeitig erkannte der Botschafter, daß die Führer des Reiches verstanden hätten, daß ohne die Zustimmung Frankreichs jede Initiative Deutschlands auf größte Schwierigkeiten stoßen werde: zuerst müsse man sich also mit Frankreich zu verständigen suchen. Ein deutsch-französisches Abkommen hätte, so vermutete André François-Poncet weiter, in den Augen Hitlers den Vorteil, das Gefühl des Friedens in Europa und der Welt zu fördern, um sein Regime zu festigen, die Aufrüstung abzuschließen, Kredit im Ausland zu finden und seine Finanzen zu entlasten. Der Haken bei deutschfranzösischen Gesprächen sei, daß Hitler sie auf die bilateralen Probleme beschränken wolle. Gleichzeitig bestünde aber - so seine Versicherung - nach der Rückkehr des Saarlandes und dem Verzicht Deutschlands auf das Elsaß kein Streitobjekt mehr zwischen den beiden Völkern. »Ce qui subsiste entre les deux peuples", schloß André François-Poncet, "ce sont les problèmes politiques de l'Europe et du monde, les problèmes que posent la volonté d'expansion de l'Allemagne, ses appétits tournés vers la Baltique, la Bohême, l'Autriche, les colonies “ ${ }^{44}$. Insofern seien die Gegenstände für deutsch-französische Gespräche umschrieben, die nur im Rahmen eines allgemeinen Abkommens festgelegt werden könnten. Das passe der deutschen Politik jedoch nicht. »Herr Hitler « zeige immer noch einen extremen Widerwillen gegen kollektive Verträge, die viele Partner verpflichteten ihre Position festzulegen. Insofern war sich der Botschafter unsicher, ob Hitlers Wunsch einer deutschfranzösischen Annäherung ihn zur Annahme des Ostpaktes führen werde ${ }^{45}$. Wie dem auch sei, die französische Außenpolitik werde sich anstrengen müssen, das Kalkül Deutschlands zu durchkreuzen.

Die Wendung in den deutschlandpolitischen Vorstellungen des französischen Botschafters ist zweitens auf die Entwicklung in Äthiopien zurückzuführen, die - so hoffte die Reichsregierung - einer deutsch-italienischen Annäherung den Weg ebnen werde ${ }^{46}$. Die Reichsregierung, die einen Krieg in Äthiopien für unvermeidlich hielt, drängte Italien zwar nicht, hielt das Land aber auch nicht zurück. »En réalité, elle se félicite de voir l'Italie se détourner du Brenner et de l'Autriche et s'engager dans une entreprise longue et difficile qui, par surcroît, risque de la brouiller avec l'Angleterre et la Société des Nations ${ }^{47}$. Reichskanzler Hitler glaubte - nicht zu Unrecht, wie die weitere und Außenminister Laval), in: DDF XV/1, Nr. 175, S. 274-278, hier S. 278.

45 Ibid.

46 Telegramm Nr. 1274 vom 20. Mai 1935, in: DDF X/1, Nr. 420, S. 626. Zu »Italiens Abessinienabenteuer « siehe ausführlich GRAML, Europa, S. $311 \mathrm{ff}$.

${ }^{47}$ Depesche Nr. 916 vom 28. Juni 1935 (Botschafter François-Poncet an Ministerpräsident und Außenminister Laval), in: DDF XI/1, Nr. 175, S. 274-278, hier S. 276. 
Entwicklung zeigen sollte -, aus dem Äthiopien-Abenteuer Mussolinis Vorteile ziehen zu können, indem der spätimperialistische Kolonialkonflikt die Verbindungen zwischen London, Rom und Paris lockere, den Völkerbund schwäche und die italienische Energie auf sich ziehe. »Ainsi les nazis et les partisans de l'Anschluss auront les coudées plus libres en Autriche, et, peutêtre, en face d'une Angleterre déjà résignée à rester neutre et d'une France dont on suppose qu'elle n'osera pas bouger, l'occasion se présentera-t-elle de réaliser le rêve, longtemps caressé, d'annexion ou de >mise au pas « ${ }^{48}$. Gleichzeitig spreche die Reichsführung von der »disparition fatale« der Tschechoslowakei. »La situation du problème autrichien est considérée comme une première étape. L'étape suivante consistera en un règlement de compte avec ce pays qu'on appelle la $>$ Tchéquie « ${ }^{49}$. Den Startschuß für die zweite Etappe würde der Angriff Japans auf Rußland geben, der die Sowjets von Europa ablenken werde ${ }^{50}$. »Avec l'aide de la Hongrie et de la Pologne, la Tchécoslovaquie sera démembrée; les états baltes seront occupés; l'Ukraine, si les circonstances restent favorables, sera conquise ... ${ }^{51}$. Angesichts dieser hinter vorgehaltener Hand zu hörenden Pläne glaubte der Botschafter die französische Außenpolitik vor den deutschen Aktivitäten in Südosteuropa warnen zu müssen:

Il est évident que l'Allemagne cherche à compliquer la situation intérieure de la Tchécoslovaquie par l'intermédiaire du parti de M. Henlein et qu'elle entretient de son mieux le conflit entre les Tchécoslovaques et les Polonais. Il est évident qu'elle persévère dans l'effort de captation auquel elle se livre sur la Yougoslavie [...] qu'elle travaille à disloquer la Petite Entente. Il est évident qu'elle s'applique à détacher la Hongrie de l'Italie, à la réconcilier avec la Yougoslavie et à se servir d'elle contre la Tchécoslovaquie, en lui faisant espérer que la Slovaquie lui écherrait dans un partage éventuel ${ }^{52}$.

Die Ziele der deutschen Außenpolitik waren André François-Poncet im Sommer 1935 mal wieder vollkommen klar. »Toute cette politique est dictée par la pensée de dissocier les formations existantes - Grande Entente, Petite Entente, Entente Balkanique, accord franco-russe, accord franco-anglais, accord italohongrois - et par l'arrière-pensée de bouleverser la carte de l'Europe, de telle manière que puisse s'établir, un jour, l'hégémonie allemande sur le continent « ${ }^{53}$. Diese Politik erkläre auch Hitlers Verzögerungstaktik gegenüber multilateralen Vertragsvorschlägen wie dem Ostpakt: »Gagner du temps semble être son principal souci. Il est convaincu que le temps, à l'extérieur, du

Depesche Nr. 981 vom 10. Juli 1935 (Botschafter François-Poncet an Ministerpräsident und Außenminister Laval), in: DDF XV1, Nr. 251, S. 373-376, hier S. 374.

49 Ibid.

50 Ibid.

51 Ibid. S. 375.

52 Ibid.

${ }^{53}$ Ibid. S. 376. 
moins, travaille pour lui. Le temps enfonce l'Italie dans l'aventure éthiopienne; il pousse la France vers les complications dramatiques d'une situation intérieure inextricable, l'Angleterre vers un désintéressement croissant à l'égard des affaires européennes ${ }^{54}$. Daß Deutschland in dem heraufziehenden Äthiopien-Konflikt »une magnifique occasion pour pêcher en eau trouble« sehe, wiederholte der Botschafter mehrfach nach der Sommerpause ${ }^{55}$. Offiziell zeige sich die Reichsregierung nach wie vor zurückhaltend und selbst die Eröffnung der Feindseligkeiten zwischen Italien und Äthiopien Anfang Oktober 1935 schien Deutschland nicht aus der Reserve zu locken ${ }^{56}$. Vielmehr betonte die Reichsregierung in der sich anschließenden Diskussion um Sanktionen gegen Italien seine Position ${ }^{57}$ : „Elle est neutre, strictement neutre ${ }^{58}$. André François-Poncet schloß aus dieser Haltung, daß sich die Reichsregierung durch ihre Zurückhaltung alle Möglichkeiten offenhalten möchte.

Bemerkenswert ist, daß André François-Poncet der französischen Außenpolitik keine Handlungsempfehlungen zum Äthiopien-Konflikt gab. Der Botschafter beschränkte sich auf seine eigentlichen Aufgaben, der französischen Regierung die deutsche Politik und der deutschen die französische nahezubringen. Diese (Selbst)Beschränkung zeichnete André François-Poncet in seiner bisherigen Amtszeit nicht unbedingt aus. Immer wieder verband er seine Analysen mit politischen Empfehlungen. Daß er diese im Sommer 1935 zurückhielt, scheint mehrere Gründe gehabt zu haben. Zunächst wird er sich nach dem Scheitern der von ihm vertretenen Stresa-Politik eine gewisse Zurückhaltung auferlegt haben, zumal er im Herbst 1934 seinen außenpolitischen Mitstreiter verloren hatte. Dessen Nachfolger, Außenminister Laval, schwenkte anschließend auf eine versöhnlichere Linie gegenüber Deutschland ein, der André François-Poncet zunächst nicht zu folgen bereit war. Jedenfalls war er im Sommer 1935 an den deutsch-französischen Gesprächen nicht beteiligt $^{59}$. Der Botschafter schwenkte - wie gesehen - erst nach einem

54 Ibid.

55 Siehe Depesche Nr. 1140 vom 7. August 1935 (Botschafter François-Poncet an Ministerpräsident und Außenminister Laval), in: DDF XI/1, Nr. 417, S. 595-599 und Depesche Nr. 1362 vom 18. September 1935 (Botschafter François-Poncet an Ministerpräsident und Außenminister Laval), in: DDF XII/1, Nr. 188, S. 273-276, Zitat S. 273.

${ }^{56}$ Vgl. Depesche Nr. 1484 vom 10. Oktober 1935 (Botschafter François-Poncet an Ministerpräsident und Außenminister Laval), in: DDF XII/1, Nr. 410, S. 587-591.

57 Siehe Telegramme Nr. 2605-2606 vom 11. Oktober 1935, in: DDF XII/1, S. 604 sowie die Telegramme Nr. 2633-2634 vom 15. Oktober 1935; Nr. 2639 vom 15. Oktober 1935 in: DDF XII/1, Nr. 460, S. 647 und Nr. 467, S. 654-655.

58 Depesche Nr. 1602 vom 7. November 1935 (Botschafter François-Poncet an Ministerpräsident und Außenminister Laval), in: DDF XIII/1, Nr. 194, S. 278-286, hier S. 279.

59 Außenminister Laval hatte - unter Umgehung André François-Poncets - eine Annäherung an Deutschland in Anlehnung an die 13 Punkte Hitlers versucht: Anfang Juni bat 
persönlichen Gespräch mit Laval Anfang November 1935 auf dessen Linie. »Je ne comprend pas votre attitude«, gestand er bei dieser Gelegenheit, »vous risquez de perdre sur les deux tableaux «, warnte er den Ministerpräsidenten, »à moins que vous n'ayez une raison très sérieuse de croire que vous pouvez arranger l'affaire d'Éthiopie avant la nouvelle année. Avez-vous cette raison?«, fragte der Botschafter den Ministerpräsidenten, der geantwortet haben soll: »Je l'ai! «" ${ }^{60}$. Diese Versicherung und das Gespräch dürften der dritte Grund und letzte Anlaß für die oben gezeigte (Rück)Wendung in den deutschlandpolitischen Vorstellungen André François-Poncets gewesen sein. Nach dieser Reorientierung hatte der Botschafter ein Gespräch mit Hitler, das zwar von einem aufsehenerregenden Kommuniqué abgeschlossen wurde, aber ohne weitergehende Folgen blieb ${ }^{61}$. Die zeitigte dagegen die von Laval angedeutete Lösung des Äthiopien-Problems. Der Laval-Hoare-Plan war Anfang Dezember 1935 Mussolini vorgelegt worden, scheiterte jedoch an der öffentlichen Meinung Großbritanniens, die über den Gebietsaustausch- und Protektoratsplan entrüstet $w^{6 r^{62}}$. Die Folgen waren weitreichend: Außenminister Hoare mußte zurücktreten, ihm folgte am 22. Dezember Anthony Eden nach. Einen Monat später stïrzte die Regierung Laval, die von einem Übergangskabinett unter der Leitung Albert Sarrauts abgelöst wurde. Entscheidend aber war, daß nach dem Scheitern des Laval-Hoare-Plans der italienische Ministerpräsident die Römischen Verträge und den Vertrag von Stresa kündigte. Mit diesem Schritt war das deutsche Kalkül - trotz der entgegenkommenden Haltung der Westmächte in der Sanktionsfrage aufgegangen: Mussolini begann, sich Hitler anzunähern ${ }^{63}$.

Insgesamt hatte sich also bis zum Jahresende 1935 die Lage so verändert, daß Hitler die nächsten Revisionsschritte in Angriff nehmen konnte. Bevor er Österreich dem Reich anschließen konnte, mußte er aus strategischen Gründen die Westgrenze Deutschlands sichern, die ja seit dem Vertrag von Locarno

er den deutschen Botschafter in Paris um »nähere Erläuterungen zur Reichstagsrede des Reichskanzlers«, siehe Schulthess' Europäischer Geschichtskalender 1935, S. 327. Wenige Tage später übernahm Laval auch noch die Ministerpräsidentschaft, so daß der Weg für eine französisch-deutsche Annäherung - an André François-Poncet vorbei - frei schien.

60 FranÇOIS-PONCET, Chronique, 9 nov.[embre 1935].

${ }^{61}$ Siehe Telegramme Nr. 2922-2924 vom 19. November 1935, in: DDF XIII/1, Nr. 252, S. 367; Telegramme Nr. 2936-249 vom 21. November 1935, in: DDF XIIU/1, Nr. 265, S. 384-386; Depesche Nr. 1657 vom 21. November 1935 (Botschafter François-Poncet an Ministerpräsident und Außenminister Laval), in: DDF XIII/1, Nr. 267, S. 388-393; Telegramme Nr. 2963-2967 vom 23. November 1935, in: DDF XIII/1, Nr. 274, S. 402f.; Depesche Nr. 1683 vom 26. November 1935 (Botschafter François-Poncet an Ministerpräsident und AuBenminister Laval), in: DDF XIII/1, Nr. 293, S. 423-428.

${ }^{63}$ Siehe GRAML, Europa, S. 329f. 
entmilitarisiert war. Der von Großbritannien und Italien garantierte Vertrag war aus deutscher Sicht nach dem französisch-sowjetischen Vertrag vom Mai 1935 Makulatur $^{64}$. Die deutschen Bedenken gegen diesen Vertrag und dessen Unvereinbarkeit mit dem Vertrag von Locarno faßte die Reichsregierung in einem Memorandum zusammen, das am 25. Mai den Locarno-Signatarmächten übergeben worden $w^{65}{ }^{65}$. Einen Monat später antwortete Paris mit einem Memorandum, das die Unvereinbarkeit der Verträge bestritt ${ }^{66}$. Die deutsch-französische Meinungsverschiedenheit blieb in den nächsten Monaten bestehen, ohne daß weitere diplomatische Aktivitäten entwickelt worden wären ${ }^{67}$. Selbst nachdem Großbritannien Anfang November seine Stellungnahme zu der Frage abgegeben hatte, schien - so die Einschätzung des französischen Botschafters - der Reichsregierung die Zeit noch nicht gekommen, die Diskussion wieder aufzunehmen ${ }^{68}$. Deutschland nehme eine abwartende Haltung ein - zumindest bis zur Klärung des italienisch-abessinischen Konfliktes $^{69}$. Vor diesem Hintergrund drängte André François-Poncet auf eine Festlegung der französischen Politik, die er in seiner Begegnung mit Laval Anfang November vorgenommen haben muß und die er in dem oben erwähnten "schéma« zusammengefaßt hatte ${ }^{70}$. Der französisch-sowjetische Vertrag sei, so hielt der Botschafter in dem Papier fest, keine offensive Militärallianz. Vielmehr sei seine Ausweitung oder sein Ersatz durch einen allgemeinen Vertag ausdrücklich vorgesehen und vorbehalten. »Dans notre intention, en tous cas, le pacte franco-soviétique s'il ouvre la route de Moscou, ne doit pas fermer celle de Berlin, ni d'aucune autre capitale. L'entente avec Berlin«, hielt der französische Botschafter fest, »ne nous paraît ni moins désirable, ni moins indispensable pour l'affermissement de la paix

${ }^{64}$ Zur deutschen Kampagne gegen den französisch-sowjetischen Vertrag siehe Telegramm Nr. 1146 vom 4. Mai 1935, in: DDF X/1, Nr. 303, S. 477-479; Telegramme Nr. 11511154 vom 5. Mai 1935, in: DDF X/1, Nr. 306, S. 480.; Telegramme Nr. 1156-1161 vom 6. Mai 1935, in: DDF X/1, Nr. 309, S. 483f.; Telegramme Nr. 1166-1169 vom 7. Mai 1935, in: DDF X/1, Nr. 313, S. 489. Zusammenfassend Depesche Nr. 615 vom 9. Mai 1935 (Botschafter François-Poncet an Außenminister Laval), in: DDF X/1, Nr. 345, S. 522-527.

65 Schulthess' Europäischer Geschichtskalender 1935, S. 124. Zum Zusammenhang DuROSELLE, Histoire diplomatique, S. $192 \mathrm{f}$.

${ }^{66}$ Schulthess' Europäischer Geschichtskalender 1935, S. 332f. Text der französischen Note, in: DDF XI/1, Nr. 145 sowie Nr. 168. Zur in Vorbereitung befindlichen deutschen Antwort vgl. Telegramme Nr. 1674-1676 vom 29. Juni 1935, in: DDF XI/1, Nr. 178, S. 281f.

67 Siehe zum Hintergrund DuroselLE, Histoire diplomatique, S. 192f.

68 Siehe Telegramme Nr. 2801-2803 vom 3. November 1935, in: DDF XIII/1, Nr. 157, S. 224f. , hier S. 225.

69 Ibid.

70 Siehe Anhang, Dokument Nr. 6: »Le but que poursuit la politique française«, S. 341-343. 
européenne ${ }^{71}$. Die revidierten Überlegungen André François-Poncets zur französischen Deutschlandpolitik sind bekannt, sie führten, wie angedeutet, zu bilateralen Gesprächen, aber zu keinem konkreten Ergebnis. Deutschland hatte den französisch-sowjetischen Vertrag immer noch nicht $»$ verdaut ${ }^{72}$. Obwohl der Vertrag in den Augen Deutschlands den von Locarno entwerte, werde die Reichsregierung - so die Einschätzung des Botschafters - frühestens in einem Jahr, d. h. Ende 1936, auf das Thema zurückkommen, weil dann die deutsche Armee einsatzbereit sein werde. Deutschland warte nur einen günstigen Zeitpunkt ab. "Et l'heure propice sonnera, pour elle, quand elle saura si l'Angleterre, la France et l'Italie doivent sortir réconciliées ou brouillées du conflit italo-abyssin et si la Société des Nations doit surmonter l'épreuve qu'elle a assumée ou être écrasée par elle ${ }^{73}$. André François-Poncet sah - je nach der internationalen Entwicklung - zwei Möglichkeiten voraus:

Ou bien les circonstances amèneront les dirigeants du $\mathrm{III}^{\mathrm{e}}$ Reich à penser qu'il y a lieu de sauvegarder l'accord de 1925 - et ils essaieront, alors, de rendre moins rigoureuse la connexion entre cet accord et le pacte franco-soviétique - ou bien l'accord de 1925 deviendra caduc; il s'écroulera, soit de lui-même et dans la débâcle des relations anglo-italofrançaises, soit à la suite d'une dénonciation formelle ${ }^{74}$.

In letzterem Fall sah der Botschafter zwei Möglichkeiten: »[...] elle occupera les garnisons et les casernes qui sont, dès maintenant, toutes prêtes, comptant que, prisonniers de nos discordes intérieures et dominés par notre amour de la paix, nous ne bougerons pas«. Oder Deutschland bevorzuge, mit Frankreich die Frage »à l'aimable« zu regeln, d. h. einen zwischen Deutschland und Frankreich zu schließenden Vertrag auszuhandeln, der keine entmilitarisierte Zone enthielte. »En tout état de cause et dans l'incertitude où elle est de l'avenir et des possibilités que celui-ci lui ménagera, elle désire réserver et maintenir ouvertes toutes les avenues ${ }^{75}$. Die entscheidende Frage sei, wie Deutschland der Weg versperrt werden könne. André François-Poncet wollte sich - wie nach dem Revirement seiner deutschlandpolitischen Vorstellungen zu erwarten - das »Dritte Reich « nicht zum Feind machen. Er warnte auch davor, aus Prinzip jeden Vorsto $B$ zurückzuweisen und alle Entspannungsvorschläge zu überhören ${ }^{76}$. André François-Poncet plädierte also für ein Eingehen auf die deutschen Verhandlungswünsche, blieb aber gegenüber der

71 Ibid.

72 Depesche Nr. 1683 vom 26. November 1935 (Botschafter François-Poncet an Ministerpräsident und Außenminister Laval), in: DDF XIII/, Nr. 293, S. 423-428, hier S. 424.

73 Ibid.

${ }^{74}$ Ibid

75 Ibid.

76 Ibid. S. 428. 
deutschen Außenpolitik skeptisch ${ }^{77}$. »Je soupçonne depuis longtemps«, schrieb der Botschafter Mitte Januar 1936, "l'Allemagne de vouloir se débarrasser, sinon du pacte de Locarno, du moins la clause par laquelle elle a, dans ce pacte, librement accepté la servitude de la zone démilitarisée ${ }^{78}$. André François-Poncet begründete seine Vermutungen mit der Haltung, die Deutschland nach wie vor gegenüber dem französisch-sowjetischen Vertrag und inzwischen auch gegenüber den britisch-französischen Mittelmeerabmachungen eingenommen hatte ${ }^{79}$. Reichskanzler Hitler habe ihm zwar immer wieder versichert, daß er keinesfalls den Vertrag von Locarno kündigen wolle. »Mais il faut se souvenir aussi que, dans son grand discours au Reichstag du 21 mai 1935, s'il a protesté de sa fidélité au pacte de Locarno, le Chancelier a ajouté qu'il le respecterait, aussi longtemps que les autres signataires le respecteraient eux-mêmes « ${ }^{80}$. Insofern erinnerte André François-Poncet an die Wiedereinführung der Wehrpflicht in Deutschland, die ja u. a. mit der Verlängerung der französischen Dienstpflicht begründet worden war. »On peut redouter dans l'affaire de Locarno un geste semblable«, schrieb André François-Poncet Mitte Januar $1936^{81}$. Die entscheidende Frage war, wann mit dem entsprechenden Schritt zu rechnen sei. Der Botschafter glaubte, daß Deutschland "pour l'instant« nicht die Absicht habe, den Vertrag von Locarno aufzukündigen. »Mais l'avenir demeure incertain ${ }^{82}$. Allein eine »sehr feste « Haltung Frankreichs in Verbindung mit Großbritannien und den führenden Völkerbundsmitgliedern könne die deutschen Pläne durchkreuzen ${ }^{83}$. Daß die Reichsregierung in der zweiten Januarhälfte die Pressekampagne gegen den französisch-sowjetischen Vertrag einstellte, beruhigte den Botschafter nicht. "L'affaire n'est pas considérée, ici, comme abandonnée, ou réglée. Elle est ajournée. [...] Elle sera évoquée de nouveau « ${ }^{84}$. Da der Ausgang des Krieges in Äthiopien und seine Ergebnisse unsicher, die Situation in Frankreich nach dem Regierungswechsel und vor den Parlamentswahlen unklar sei und der neue Außenminister Großbritanniens, Eden, seine Politik noch nicht geklärt

77 Zur deutschen Politik gegen den französisch-sowjetischen Vertrag und damit auch gegen den Vertrag von Locarno vgl. Depesche Nr. 52 vom 8. Januar 1936 (Botschafter François-Poncet an Ministerpräsident und Außenminister Laval), in: DDF I/2, Nr. 24, S. 31-34.

78 Telegramme Nr. 114-115 vom 14. Januar 1936, in: DDF I/2, Nr. 49, S. 71-76, hier S. 74.

79 Ibid.

${ }^{80}$ Ibid. S. 75.

81 Ibid.

82 Ibid.

${ }^{83}$ Depesche Nr. 106 vom 16. Januar 1936 (Botschafter François-Poncet an Ministerpräsident und Außenminister Laval), in: DDF I/2, Nr. 73, S. 105.

84 Telegramm Nr. 227 vom 22. Januar 1936, in: DDF I/2, Nr. 95, S. 141. 
habe, werde die deutsche Außenpolitik ihre abwartende Haltung beibehalten ${ }^{85}$. Gegenteilige Anfragen des französischen Außenministeriums ${ }^{86}$ beantwortete der Botschafter zuversichtlich: Mit einem fait accompli sei im Moment nicht zu rechnen. Gleichwohl glaubte André François-Poncet nach wie vor, daß die deutsche Diplomatie die Frage noch ansprechen werde ${ }^{87}$.

Wenige Tage später schienen Deutschland nach den französisch-britischen Gesprächen in Paris und nach der Abstimmung in der französischen Abgeordnetenkammer die günstigen Umstände gekommen, um die Diskussion über die Vereinbarkeit des französisch-sowjetischen Vertrages mit dem von Locarno wieder zu eröffnen ${ }^{88}$. Da die Garantiemächte, die in diesem Fall die besten Schiedsrichter seien, die Vereinbarkeit der Verträge erklärt hätten, sah André François-Poncet nicht, wie Deutschland beabsichtigen könne, seine Ansicht durchzusetzen. Gleichwohl blieben dem Botschafter Zweifel: »On [redoute] qu'elle n'ait l'intention de brusquer les choses et de procéder, comme l'hypothèse n'en est pas invraisemblable, à une dénonciation pure et simple $"{ }^{89}$. Entsprechende Gerüchte machten zwar in Berlin die Runde, wurden aber von André François-Poncet nicht geglaubt, der den Versicherungen des Außenministers von Neurath vertraute und deshalb eine plötzliche Besetzung des Rheinlandes in den »nächsten Wochen« für »unwahrscheinlich« hielt ${ }^{90}$. Die Aufkündigung des Vertrages von Locarno erschien dem Botschafter eher möglich. Allerdings war sich André François-Poncet unsicher, da eine Kündigung der Verträge von 1925 Deutschland eine englisch-italienische Garantie nähme, von der Frankreich weiter profitieren könnte. »Le Reich souhaiterait donc, plutôt, ouvrir un débat d'où il compterait faire sortir un traité amendé, précisé et, en quelque manière, moins lourd pour lui«" ${ }^{91}$ Der französische Botschafter war optimistisch, daß sich die zögernden Verantwortlichen nicht vom Kreis der Großmächte ausschließen wollten. »À moins d'un coup de tête ou d'un accès de violence auquel ils seront toujours capables de se laisser aller, il est permis de penser qu'ils n'ont pas définitivement fermé leurs oreilles aux suggestions de la prudence et de sagesse ${ }^{92}$. Trotz des zur Schau getragenen Optimismus versuchte der Botschafter weiter, die mögliche Reaktion Deutschlands auf die Ratifikation des französisch-sowjetischen Vertrages

85 Telegramme Nr. 324-329 vom 31. Januar 1936, in: DDF I/2, Nr. 116, S. $164 f$.

${ }^{86}$ Vgl. Telegramm Nr. 94 vom 6. Februar 1936, in: DDF I/2, Nr. 138, S. 198.

87 Telegramme Nr. 386-388 vom 7. Februar 1936, in: DDF I/2, Nr. 147, S. 213.

88 Telegramme Nr. 419-423 vom 10. Februar 1936, in: DDF I/2, Nr. 162, S. $231 \mathrm{f}$.

89 Ibid. S. 232.

${ }^{90}$ Depesche Nr. 288 vom 13. Februar 1936 (Botschafter François-Poncet an Außenminister Flandin), in: DDF V/2, Nr. 180, S. 256-261, hier S. 260.

91 Ibid.

92 Ibid. S. 261. 
herauszufinden ${ }^{93}$. Sie blieb - trotz aller Bemühungen - unklar. Deutschland schien die Reaktion noch nicht festgelegt zu haben. André François-Poncet machte, wie üblich in unentschiedenen Situationen, zwei Strömungen aus: "Celui des exaltés, des têtes chaudes, qui poussent aux actes prompts et audacieux, dussent-ils être l'origine de conflits graves, et la tendance des esprits pondérés, qui mesurent les risques, constatent l'isolement du Reich et conseillent la temporisation et la prudence ${ }^{94}$. Daß Deutschland die Entwicklung noch nicht überstürzt habe und zur plötzlichen Besetzung des Rheinlandes geschritten sei, sei zum Teil Großbritannien zu verdanken, das den Vertrag von Locarno für gültig betrachte und seine Verpflichtungen zu erfüllen gewillt sei. Vor diesem Hintergrund glaubte André François-Poncet Ende Februar 1936 noch, daß Deutschland Zeit gewinnen wolle ${ }^{95}$. Allerdings werde die Ratifikation des französisch-sowjetischen Vertrages nicht wortlos hingenommen werden. Deutschland fühle sich moralisch verpflichtet, schon aus Prestigegründen, eine Geste zu machen.

Elle évitera probablement [Hervorhebung im Original, cws] l'irrémédiable, c'est-à-dire ce qui pourrait créer un péril de guerre, qu'elle ne se juge pas, à l'heure actuelle, en état d'assumer. Elle ne violera pas ouvertement le pacte de Locamo. Elle ne procédera pas à une occupation militaire soudaine de la zone rhénane. Plus vraisemblablement, elle protestera, sous une forme ou sous une autre - démarche, discours, mémorandum? - afin de préciser sa position, de prendre date et de se réserver l'avenir. Elle essayera de faire dénoncer par l'Italie le traité de 1925. [...] Elle demandera, peut-être, l'ouverture d'une négociation entre les signataires des actes de 1925, pour examiner une situation qui s'est modifiée et en espérant que l'Angleterre l'aidera à obtenir l'atténuation, sinon l'abolition, de la clause de démilitarisation de la zone rhénane ${ }^{96}$.

Hitler werde die Reaktion erst im letzten Moment festlegen, und so lange werde Europa auch nicht vor einer unüberlegten Tat oder überraschenden Wendung gefeit sein. »De toute facon«, schloß der französische Botschafter, "l'Angleterre et la France n'auront qu'avantage à ne pas affranchir l'Allemagne de l'embarras d'un choix si capital, à ne pas clore de leurs propres mains, les portes de la sagesse et du retour à la raison, afin que la responsabilité des événements qui pourront surgir, et qui pourraient être graves, incombe au Reich, à lui seul et à son régime «" ${ }^{97}$. Insofern hatte André FrançoisPoncet auch für eine deutsch-französische Kontaktaufnahme nach der Veröffentlichung des berühmten Hitler-Jouvenel-Interviews plädiert, obwohl die Äußerungen im Vergleich zu den Aussagen am 21. November 1935 nichts

93 Telegramme Nr. 555-556 vom 22. Februar 1936, in: DDF 1/2, Nr. 214, S. 311.

94 Depesche Nr. 369 vom 27. Februar 1936 (Botschafter François-Poncet an Außenminister Flandin), in: DDF I/2, Nr. 242, S. 340-344, hier S. 342.

95 Ibid. S. 343.

96 Ibid. S. 344.

97 Ibid. 
Neues enthielten ${ }^{98}$. Gegenüber dem Botschafter zeigte sich der Reichskanzler zurückhaltender. Er wolle die deutsch-französischen Gespräche nicht absagen, sondern nur aufschieben, also Zeit gewinnen ${ }^{99}$. Insofern hielt André FrançoisPoncet seinen Schritt für opportun, weil er Frankreich erlaubt hätte, einen Punkt zu machen und weiter erlauben würde, Punkte zu machen. Denn Hitler bringe seine Vorschläge, wie er in einer ausführlichen Analyse des Gespräches feststellte, zum Großteil aus taktischen Gründen vor ${ }^{100}$. Bisher seien die französischen Regierungen noch nicht auf sie eingegangen. $\mathrm{Da} B$ die aktuelle Regierung das tat, habe den Reichskanzler gestört, sein Spiel durchkreuzt. Für André François-Poncet stand inzwischen fest, daß Deutschland 1936 die Demilitarisierung des Rheinlandes aufheben oder abschwächen wolle ${ }^{101}$.

Die Frage war, wie das »Dritte Reich« das Ziel anstreben werde und was es im Gegenzug Frankreich anbieten werde. Wenn eine Rückkehr nach Genf, eine Zustimmung zur kollektiven Politik als ausreichender Preis verstanden werden würde, wäre Hitler-Deutschland heute nicht bereit, ihn zu zahlen ${ }^{102}$. Gleichzeitig wollten die Führer des Reiches aus Angst vor kriegerischen Komplikationen die Sache nicht überstürzen ${ }^{103}$. Vor diesem Hintergnund fragte sich der Botschafter, ob sie nicht die Unvereinbarkeitsthese als juristischen Vorwand für spätere Initiativen aufrechterhalten wollten. Der Reichskanzler hatte sich dem im Februar 1935 initiierten Luftpakt anschließen wollen, weil, so der Eindruck des Botschafters, er in einem bestimmten Maß den französisch-sowjetischen Vertrag ausgleichen würde. »Il est à souhaiter que le Führer s'engage dans cette voie; car il est d'importance que le contact soit pris une fois avec lui et que, pour ainsi dire, un bout de la corde puisse être saisi. En la suivant, en la dévidant, on réussira, peut-être, à éclaircir les malentendus, à calmer des inquiétudes et à réaliser des progrès « ${ }^{104}$. André FrançoisPoncet plädierte also für die Aufnahme von Verhandlungen, ohne sich allzu große Hoffnungen zu machen:

Je ne nourris, certes, aucun espoir excessif; mais je ne suis pas, non plus, dénué de tout espoir. L'Allemagne est, présentement, dans une situation pénible; son économie, ses finances sont entrées dans une crise redoutable. Il y a, autour du Führer, des hommes comme M. Schacht, qui insisteront sur la nécessité d'une détente européenne, et même d'une

98 Zum Hitler-Interview siehe Telegramm Nr. 636 vom 29. Februar 1936, in: DDF V/2, Nr. 255, S. 361. Einzelheiten im Telegramm Nr. 743 vom 9. März 1936, in: DDF I/2, Nr. 349 , S. 458-460.

99 Telegramm Nr. 650 vom 2. März 1936, in: DDF I/2, Nr. 265, S. 373-375, hier S. 375.

${ }^{100}$ Depesche Nr. 400 vom 3. März 1936 (Botschafter François-Poncet an Außenminister Flandin), in: DDF $1 / 2$, Nr. 272, S. 381-385, hier S. 382.

${ }^{101}$ Ibid. S. 383.

102 Ibid.

${ }^{103}$ Ibid. S. 384.

104 Ibid. 
amélioration des rapports germano-russes, qui soulageraient le III $^{\mathfrak{e}}$ Reich et rendraient à l'Allemagne un peu d'oxygène ${ }^{105}$.

In diesem Sinne hätte sein Gespräch vom 2. März unbestreitbaren Nutzen. Der Botschafter erinnerte daran, für wie bedauerlich er es hielt, die Freundschaftsbeweise des Führers unbeantwortet zu lassen. "Il ne faut pas qu'un jour M. Hitler puisse tirer avantage des offres répétées qu'il nous a adressées sans que nous les relevions, et soit fondé à soutenir que nous ne lui avons laissé d'autre ressource que le recours à la violence « ${ }^{106}$. Insofern scheint André François-Poncets (Rück)Wendung zur kooperativen Deutschlandpolitik in jeder Hinsicht taktischer Natur gewesen zu sein. Der Botschafter wollte - wie gezeigt werden konnte - Deutschland die Verantwortung für die weitere Entwicklung zuschieben. Er ist mithin zu einer kooperativen Politik zurückgekehrt, die er aber mit völlig anderen Motiven verfolgte.

André François-Poncet wurde drei Tage später, am 6. März, zum 7. März ins Auswärtige Amt einbestellt. Aus der Tatsache, daß auch der britische Botschafter und der belgische Geschäftsträger einbestellt worden seien, schloß André François-Poncet, daß er eine Note an die Unterzeichner des Vertrages von Locarno erhalten werde ${ }^{107}$. »Ou bien $\mathrm{M}$. Hitler déclarerait que Locarno est devenu caduc et notifierait la réoccupation prochaine de la zone démilitarisée. Ou bien il adresserait à l'Europe et à la France en particulier, une nouvelle déclaration pacifiste; ou bien il dirait que l'Allemagne est prête à rentrer à la Société des Nations, moyennant certaines conditions, parmi lesquelles figurerait une modification du statut thénan ${ }^{108}$. Letzteres werde in Berlin als wahrscheinlichstes betrachtet. »Mais«, fügte André François-Poncet hinzu, »la première ne doit pas être tenue pour invraisemblable. En réalité, on ignore toujours qui, des partisans de la modération ou de ceux de la violence, l'a finalement emporté dans les conseils de ses derniers jours ${ }^{109}$. Tatsächlich ließ Hitler am Samstag, 7. März 1936, deutsche Truppen ins Rheinland einmarschieren. Die Botschafter der Locarno-Signatarmächte wurden im Laufe des Vormittags von Außenminister von Neurath über den Schritt informiert. Der französische Botschafter, der, nach seinem italienischen Kollegen, um $10 \mathrm{Uhr}$ 30 an die Reihe kam, erhielt ein Memorandum, das eine Aufkündigung des

105 Ibid.

${ }^{106}$ Ibid. S. 384f.

107 Telegramm Nr. 696 vom 6. März 1936, in: DDF I/2, Nr. 288, S. 400f.

${ }^{108}$ Siehe Telegramm Nr. 700 vom 6. März 1936, DDF I/2, Nr. 291, S. 402f.; Telegramm Nr. 701 vom 6. März, DDF I/2, Nr. 292, S. 403f.; Telegramme Nr. 702-706 vom 6. März 1936, DDF I/2, Nr. 293, S. 404f.; Telegramme Nr. 707-708 vom 6. März 1936, in: DDF U/2, Nr. 294, S. 405, Zitat ibid.

${ }^{109}$ Telegramme Nr. 707-708 vom 6. März 1936, in: DDF I/2, Nr. 294, S. 405. Siehe auch kritisch Stéphane ROUSSEl, Die Hügel von Berlin. Erinnerungen an Deutschland, Reinbek 1989, S. 227-231. 
Vertrages von Locarno und ein Angebot zu Verhandlungen über den Abschluß eines neuen Vertrages enthielt ${ }^{110}$. André François-Poncet protestierte »de la manière la plus énergique et la plus solennelle« gegen den Schritt, in dem er eine "einseitige Aufkündigung bestehender Verträge« sah, »un acte non seulement contraire au traité de Versailles, mais encore au traité de Locarno, librement discuté et accepté par l'Allemagne «" ${ }^{111}$. Der Botschafter stellte fest, $\mathrm{da} B$ Deutschland die Ratifikation des französisch-sowjetischen Vertrages als Vorwand genutzt habe, um diesen »fait accompli« zu schaffen. »Elle s'arrogeait arbitrairement un droit, par une méthode qui rendait singulièrement difficile de se prêter à sa suggestion, et singulièrement peu tentante à la perspective d'entrer avec elle dans des arrangements futurs ${ }^{112}$. Diese beim Austritt aus dem Völkerbund am 14. Oktober 1933 und bei der Einführung der Wehrpflicht am 16. März 1935 angewandte Methode könne die von der Reichsregierung gewünschte Herrschaft der Eintracht und des Friedens in Europa nicht herbeiführen. Reichsaußenminister von Neurath versicherte dem Botschafter, daß Deutschland die Tür nach Frankreich nicht verschließen wolle, sondern die Unterhaltung vom 2. März, auf der Grundlage des überreichten Memorandums, fortzusetzen wünsche. André François-Poncet erwartete gleichwohl eine scharfe Reaktion seiner Regierung:

Pour ma part, il me paraît difficile que le gouvemement français accepte le fait accompli délibérément créé par le gouvernement allemand sans réagir avec vigueur. À mon sens il devait être en tout cas signifié dans les plus brefs délais à $\mathbf{M}$. Hitler que la dignité de la France lui interdit d'engager avec lui une négociation sous la pression des mesures militaires prises dans la zone rhénane, même si ces mesures ne doivent avoir qu'une valeur de symbole $^{113}$.

Der Botschafter lehnte also weitere deutsch-französische Verhandlungen ab, wenngleich er das zu bedauern schien ${ }^{114}$. Daß Deutschland zu diesem Zeitpunkt das seit Juni 1935 über Europa schwebende Damokles-Schwert fallen ließ, führte André François-Poncet auf zwei Gründe zurück: Erstens habe die deutsche Armee in der Zwischenzeit erheblich an Stärke gewonnen und zweitens sei Europa heute geteilt. Deutschland glaube, daß das Friedensangebot an Italien scheitern werde, so daß Spannungen, vielleicht ein Krieg, zwischen Italien, Frankreich und Großbritannien entstünden und daß der mit dem Äthiopien-Konflikt belastete Völkerbund weder die Zeit noch die Mittel habe, sich ernsthaft mit dem Rheinland zu beschäftigen. Letztlich hoffe Deutsch-

\footnotetext{
${ }^{110}$ Siehe Hildebrand, Vergangenes Reich, S. 706.

${ }^{111}$ Telegramm Nr. 709 vom 7. März 1936, in: DDF I/2, Nr. 298, S. 410f., hier S. 410.

${ }^{112}$ Ibid. S. $410 f$.

${ }^{113}$ Vgl. Telegramme Nr. 710-712 vom 7. März 1936, in: DDF I/2, Nr. 299, S. 412.

${ }^{114}$ Telegramme Nr. 715-720 vom 7. März 1936, in: DDF I/2, Nr. 304, S. $416 f$.
} 
land, die öffentliche Meinung Großbritanniens mit seinem Vorschlag einer Rückkehr nach Genf und einem Luftpakt gewinnen zu können ${ }^{115}$.

Die Aufkündigung der Verträge von 1925 und das Angebot neuer Verträge überraschte André François-Poncet nicht ${ }^{16}$. Er hatte das - wie gesehen immer wieder vorhergesagt. In der Remilitarisierung des Rheinlandes, der Verkündung der allgemeinen Wehrpflicht und dem Austritt Deutschlands aus dem Völkerbund erkannte der Botschafter nicht nur eine »einheitliche Methode «, sondern auch aufeinander aufbauende "Initiativen «. »Ces trois opérations ne sont pas des épisodes isolés; elles forment une chaîne, ou plutôt les anneaux d'une chaîne et de cette chaîne rien n'indique que nous ayons atteint le bout ${ }^{117}$. Die Ziele des Reichskanzlers beschränkten sich nicht auf die Wiederherstellung der vollen Souveränität. "Le III $^{\mathfrak{e}}$ Reich est bien décidé à aller plus haut et plus loin que l'Empire de Guillaume II ${ }^{118}$. Das nächste Ziel werde, so die Vorhersage des Botschafters, die »Eroberung « Österreichs sein. André François-Poncet glaubte aber auch, ein Gegenmittel zu kennen. "Les chefs du national-socialisme, ou, du moins les plus réfléchis d'entre eux, redoutent la guerre; car ils savent que leur pays n'est pas encore en mesure de résister victorieusement à la pression simultanée qu'auraient à subir divers secteurs de ses frontières ${ }^{119}$. Sie seien aber überzeugt, und mit ihnen wohl auch der Botschafter, daß der Völkerbund keinen Krieg erklären könne und $\mathrm{da} B$ das französische Volk sich freiwillig nur für den eigenen Boden schlagen werde. Was noch blieb, waren Wirtschaftssanktionen. »Si elles étaient résolues et réalisées avec rigueur, si l'Angleterre, l'Amérique, la Belgique, les États baltes et scandinaves y participaient, l'Allemagne se trouverait rapidement placée dans une situation cruelle ${ }^{120}$. Gleichwohl scheinen sie nach den Erfahrungen Italiens - Sanktionen nicht zu fürchten. Außerdem würde Deutschland wohl bei einer Blockade zu den Waffen greifen. Infolgedessen stünden der Völkerbund insgesamt sowie Frankreich und Großbritannien im besonderen vor einem Dilemma: »Que la Société des nations, et particulièrement la France et l'Angleterre, se montrent faibles, comme elles l'ont été après le 14 octobre 1933 et le 16 mars 1935, elles accroîtront non seulement le prestige intérieur et extérieur d'Adolf Hitler, mais son ambition et sa hardiesse. Qu'elles soient énergiques et réagissent fortement, la guerre

${ }^{115}$ Telegramme Nr. 721-722 vom 7. März 1936, in: DDF V/2, Nr. 305, S. 417f.

${ }^{116}$ Siehe auch Depesche Nr. 431 vom 10. März 1936 (Botschafter François-Poncet an AuBenminister Flandin), in: DDF I/2, Nr. 379, S. 491 f.

${ }^{117}$ Depesche Nr. 428 vom 9. März 1936 (Botschafter François-Poncet an Außenminister Flandin), in: DDF $\mathrm{I} / 2$, Nr. 350, S. 461-467, hier S. 463.

118 Ibid.

119 Ibid.

${ }^{120}$ Ibid. 
risque d'en résulter “ ${ }^{121}$. André François-Poncet redete einem Krieg zwar nicht das Wort, aber er schien ihm kaum mehr vermeidbar. »L'Allemagne«, betonte der Botschafter, »est pacifique, aujourd'hui, en attendant qu'elle soit belliqueuse demain et que son armée, fiévreusement reconstituée, et devenue la plus puissante d'Europe, la mette en mesure de se procurer de la force qui ne lui aura pas été concédée de gré. On connaît ce raisonnement; on connaît cette politique; ils ont conduit à la guerre de 1914 « $^{122}$. Vor dem Hintergrund schien dem Botschafter wieder einmal die britische Haltung entscheidend: "Si l'Angleterre mollit, si elle cède, $M$. Hitler aura gagné. Si elle défend le droit et la morale, le cas de M. Hitler deviendra mauvais ${ }^{123}$.

Während die erste Reaktion der französischen Regierung - Ministerpräsident Sarraut sagte im Radio, Straßburg werde nicht unter deutschen Kanonen bleiben - in Berlin mit Überraschung und Beunruhigung aufgenommen wurde, erleichterte die Reaktion Londons die Berliner Gemüter ${ }^{124}$. Entgegen dem Wunsch des Botschafters hielt sich die französische Regierung mit weiteren Reaktionen zuruick, da die Rheinlandbesetzung keine "menace la plus immédiate pour la collectivité des États membres de la Société des Nations « darstelle $^{125}$. Gleichzeitig versuchte Frankreich, Großbritannien auf eine härtere Linie zu ziehen ${ }^{126}$. Diese Bemühungen konterkarierte der Reichskanzler mit dem Ward Price gegebenen Interview. Insgesamt schien das deutsche Kalkül aufzugehen: Außer einer formalen Zurückweisung der Vertragsverletzung unternehme London nichts, was die angedrohte Zurücknahme der Angebote herbeiführen könnte. Durch die Haltung Großbritanniens sei Frankreich paralysiert, wie André François-Poncet festhielt:

Elle doit regretter de n'avoir pas répondu au geste brutal du 7 mars par un geste de même nature, à l'occupation militaire de la Rhénanie, par la mobilisation et la saisie d'un gage. Elle n'en est pas moins réduite à l'état d'infériorité de celui qui reste dans la légalité, vis-à-vis de celui qui s'en est affranchi et qui ne se heurte pas à la solidarité répressive des organismes chargés de veiller sur le bon ordre et la paix ${ }^{127}$.

Das habe Deutschland verstanden und fühle sich, nach ein, zwei Tagen der Unsicherheit und der Unruhe, wieder »sicher «, daß das »Abenteuer« nicht

${ }^{121}$ Ibid. S. 464.

${ }^{122}$ Ibid. S. 466f.

${ }^{123}$ Ibid. S. 466.

${ }^{124}$ Vgl. Telegramme Nr. 736-737 vom 9. März 1936, in: DDF I/2, Nr. 337, S. 449 und Telegramme Nr. 754-757 vom 10. März 1936, in: DDF I/2, Nr. 359, S. 475f. Zu den Reaktionen der Signatarmächte siehe DUROSELLE, Histoire diplomatique, S. 194ff.

125 Telegramm Nr. 190 vom 10. März 1936, in: DDF I/2, Nr. 372, S. 484f. Siehe auch DUROSELLE, Décadence, S. 168ff. und REMOND, Siècle, S. 184.

${ }^{126}$ Telegramme Nr. 192-195 vom 11. März 1936, in: DDF I/2, Nr. 380, S. 493f.

${ }^{127}$ Depesche Nr. 486 vom 17. März 1936 (Botschafter François-Poncet an Außenminister Flandin), in: DDF V2, Nr. 449, S. 580-582, hier S. 580. 
schlecht für das Land ausgehen werde ${ }^{128}$. Diese Möglichkeit - »désastreuse pour la France et pour l'Europe « - müsse um jeden Preis verhindert werden. Frankreich blieben, so die Einschätzung des Botschafters, zwei Optionen: Die radikale Haltung bedeute die Umsetzung der französischen Drohungen, also den Rückzug aus dem Völkerbund, dem andere folgen würden, und den Wiederaufbau der Vorkriegsallianzen, indem Frankreich sich enger an Rußland, die Kleine Entente und Italien anzuschließen versuche. Demgegenüber könne noch der Weg der Verhandlungen beschritten werden, um aus dem vorgeschlagenen System das Maximum an Vorteilen herauszuziehen und es gleichzeitig mit Rückversicherungen gegen einen weiteren Vertragsbruch Deutschlands abzusichern. Ein entsprechendes Projekt sei, so erinnerte der Botschafter an seinen Vorschlag, schon in der Abrïstungskonvention vorgeschlagen worden. Jedenfalls dürfe Hitler in seinem Vorgehen nicht bestärkt und damit auch nicht sein Prestige gestärkt werden ${ }^{129}$. Dies werde erreicht, wenn sich Europa gegenuiber Deutschland in einem Vertrag einigt. Daß der Zynismus und die Brutalität des »Dritten Reiches« andernfalls triumphieren würden, schien André François-Poncet klar. »Si ses adversaires demeurent dans le droit, le droit les lie et ne le lie pas. Ils lui sont donc inférieurs. Mais ainsi se prépare un avenir de catastrophe. Encouragé par le succès et l'impunité, l'État en question persévère; il tente un nouveau coup; cette fois, les autres se révoltent; une guerre générale éclate. Et c'est à quoi,« hielt der Botschafter fest, »nous assisterons ${ }^{130}$. Hitler beteuere zwar immer wieder, daß er am Frieden arbeite, der aber ein deutscher Friede sei, durch Gewalt oder Drohungen hergestellt ${ }^{131}$. André François-Poncet war überzeugt, daß das »Dritte Reich« Gefangener seiner »Dynamik« und verurteilt sei, sich in immer neue Abenteuer zu stürzen.

Ainsi, la loi du III ${ }^{e}$ Reich est de se dépasser constamment soi-même, jusqu'au moment où, se heurtant au monde, il asservira le monde, ou volera en éclats. S'il y avait eu, dans le camp des puissances locarniennes et au Conseil de la Société des Nations, solidarité, unanimité, énergie pour repousser et réprimer le coup de force du 7 mars, si le mémorandum élaboré à Londres avait été exécuté, coûte que coûte, M. Hitler serait, sans doute, devenu plus prudent. Mais l'expérience l'aura, une fois de plus, convaincu qu'il ne s'était pas trompé en tablant sur la timidité des démocraties, sur la peur des responsabilités de leurs hommes d'État et sur l'impuissance de la Société des Nations. Toute la question est donc de savoir, non pas si M. Hitler observera la paix qu'il offre généreusement à l'Europe pour vingt-cinq ans, mais quand et contre qui se tourneront ses initiatives ultérieures ${ }^{132}$.

${ }^{128}$ Ibid. S. 581.

${ }^{129}$ Ibid. S. 582.

${ }^{130}$ Depesche Nr. 521 vom 25. März 1936 (Botschafter François-Poncet an Außenminister Flandin), in: DDF I/2, Nr. 503, S. 656-664, hier S. 660.

${ }^{131}$ Ibid. S. 661.

${ }^{132}$ Ibid. 
Österreich und die Tschechoslowakei würden, so die Vermutung des Botschafters, die nächsten Opfer sein. Denn Hitler habe den Vertrag von Locarno zerrissen, um an der deutschen Westgrenze ein unüberwindliches Hindernis zu errichten, so daß er die Hände frei habe im Süden und Südosten. Allerdings sei angesichts der Haltung und Politik Frankreichs nicht auszuschließen, daß sich Hitler daran erinnert, wo der Hauptfeind Deutschlands steht. Infolgedessen befinde sich nicht nur Europa, sondern auch Frankreich in Kriegsgefahr. Wie die französische Außenpolitik dieser Gefahr begegnen sollte, ist im nächsten Abschnitt eingehender zu untersuchen. Festzuhalten bleibt einstweilen, daß André François-Poncet nach dem 7. März 1936 seinen deutschlandpolitischen Vorstellungen treu blieb und nach wie vor versuchen wollte, das Reich durch Verträge zu binden, um ihm im Zweifelsfall die Schuld an kriegerischen Verwicklungen zuschieben zu können.

\subsection{Letzte Chancen}

Den bei der Aufkündigung des Vertrages von Locarno in Aussicht gestellten Verhandlungen über einen neuen Vertrag ließ Reichskanzler Hitler einen sogenannten Friedensplan folgen, den er Ende März in einer großen Rede vor dem Reichstag vorstellte ${ }^{133}$. André François-Poncet reiste mit dem am

${ }^{133}$ André François-Poncet hatte den wahrscheinlichen Inhalt zwei Tage vorher nach Paris telegrafiert: Die Gegenvorschläge Hitlers würden den Gedanken der 25jährigen Nichtangriffsverträge, die schon am 7. März den östlichen Nachbam Deutschlands angeboten worden waren, präzisieren und ausweiten. Den westlichen Mächten würde wahrscheinlich ein neuer Locarno-Vertrag vorgeschlagen werden, der außer einer Nichtangriffsverpflichtung auch eine gegenseitige Hilfsverpflichtung und einen Luftpakt enthalte. Außerdem würde der „Führer« wahrscheinlich das Problem der Rüstungsbeschränkung ansprechen. Bei den kurzfristigen im Rheinland anzuwendenden Maßnahmen, die Gegenstand sofortiger Verhandlungen sein könnten, blieben die Absichten der Reichsregierung bis jetzt undurchdringlich, weil der $»$ Meister« nicht anwesend sei. Die Wilhelmstraße überprüfe vorsichtig verschiedene Möglichkeiten. Die ganze Aufmerksamkeit zögen in Berlin so und so die britisch-französisch-belgischen Generalstabsgespräche auf sich. »Si un tel accord avait existé avant le 7 mars«, hielt André François-Poncet fest, »'Allemagne n'aurait pas réoccupé la Rhénanie«. Der Botschafter ging sogar so weit, daB Deutschland am 7. März das Rheinland besetzt habe, weil die Befürchtung bestand, daß dieser Vertrag bald zustande kommen würde. Zwischen dem 2. und 4. März müsse Hitler gewarnt worden sein, daB Frankreich, einen Gewaltstreich Deutschland vorhersehend, einen Aktionsplan ausarbeite, dem Großbritannien beitreten solle. »Il aurait alors décidé de jouer le tout pour le tout et donné à la Reichswehr les instructions que celle-ci, prise à l'improviste, a exécutées non sans confusion et désordre «, vgl. Telegramme Nr. 1016-1020 vom 29. März 1936, in: DDF I/2, Nr. 527, S. 702f. Zum deutschen 
gleichen Tag den Botschaftern in Berlin übergebenen Papier nach Paris, wo er an einer Konferenz der französischen Botschafter in Berlin, London und Rom mit dem Außenminister und dem Ministerpräsidenten im Außenministerium teilnahm ${ }^{134}$. André François-Poncet sah in dem Friedensplan Hitlers ein Ablenkungsmanöver. Die äußeren Angelegenheiten erschienen vielen in Deutschland als "un moyen de détourner l'attention « von der sich verschlechternden wirtschaftlichen und finanziellen Lage Deutschlands. Gleichzeitig fürchte Deutschland vor allem eine französisch-britische Allianz, die Wiedererrichtung der Stresafront und die Isolation und Verurteilung Europas. Infolgedessen wünschte André François-Poncet eine wie auch immer geartete Koalition gegen Deutschland, das so isoliert und zur Vernunft gebracht werden sollte. Sanktionen würden in Berlin nicht gefürchtet, obwohl sie nach Einschätzung des Botschafters »un grave danger de guerre « beinhalteten, weil Hitler versucht sein könne, sie mit Gewalt zu brechen. »Hitler est sur la pente de la guerre «, hielt André François-Poncet fest. »Il ne parle de paix que parce qu'il sent la guerre sous-jacente«. Er denke nur an brutale Methoden. »Il déclare à tout le monde qu'il faut savoir assumer le risque des guerres. Toute l'évolution du régime tend à cette éventualité. Hitler ne reculera pas devant ce risque, sauf s'il trouve devant lui une coalition assez redoutable ${ }^{135}$.

Trotz dieser »Kriegspolitik « und der von dem Botschafter geforderten antideutschen Koalitionspolitik wollte André François-Poncet den Gesprächsfaden nicht abreißen lassen. Sein Ziel: Hitler sollte gezwungen werden, seine Vorstellungen zu präzisieren. Hitler habe seine Überlegungen nicht bis zu Ende gedacht; sie strotzten vor Widersprüchen. Er biete gegenseitige Hilfe im Westen an, warum nicht im Osten? Warum will Deutschland im Westen eine andere Politik betreiben als im Osten? Ziel der von André François-Poncet ins Auge gefaßten Gespräche war, die deutsche List mit einer (französischen) Gegenlist zu überlisten ${ }^{136}$. Der Botschafter wollte die bündnispolitische Absicherung Frankreichs mit deutsch-französischen Verhandlungen flankieren. Er plädierte also für eine Doppelstrategie, die - je nach Entwicklung der internationalen Situation - Frankreich zwei Optionen offenhielt: Eine Zukunft mit oder gegen Deutschland. Grundlage der Vorgehensweise war die Überzeugung, der deutschen Außenpolitik wie auch Hitler mit rationalen Überlegungen Herr werden zu können. Daß der Reichskanzler im Zweifelsfall ver-

"Friedensplan« siehe Schulthess' Europäischer Geschichtskalender 1936, S. 75-80. Zur Analyse André François-Poncets siehe Depesche Nr. 614 vom 9. April 1936 (Botschafter François-Poncet an Außenminister Flandin), in: DDF II/2, Nr. 47, S. 92-97.

${ }^{134}$ Vgl. Compte rendu der Botschafterbesprechung, in: DDF II/2, Nr. 17, S. 26-40. Zum

Zusammenhang siehe DUROSELLE, Décadence, S. 177.

${ }^{135}$ Compte rendu der Botschafterbesprechung, in: DDF II/2, Nr. 17, S. 29.

${ }^{136}$ Ibid. 
nünftige Einwände mit einem Handstreich beiseite schob, ahnte André François-Poncet zwar, konnte diese Irrationalität aber nicht seinen deutschlandpolitischen Überlegungen zugrunde legen, weil sie die Grundlage seiner Arbeit zerstört hätten. Internationale (Macht)Politik basiert auf nationalen Interessen und folgt rationalen Kosten-Nutzen-Überlegungen. Werden diese außer acht gelassen, wird Außenpolitik unberechenbar, die Aufgabe eines Botschafters unlösbar.

Vor diesem Hintergrund mußte André François-Poncet, wenn er Botschafter bleiben wollte, auf die Rationalität der deutschen Außenpolitik vertrauen. Daß diese aus solchen Überlegungen heraus das remilitarisierte Rheinland sobald wie möglich befestigen wollte, um sich für die geplanten Aktionen in Ost- und Südosteuropa den Rücken frei zu halten, schien dem Botschafter sicher. Die Außenminister Flandin und die Militärs besonders interessierende Frage der Befestigung des linken Rheinufers und der möglichen deutsch-französischen Gespräche zu dieser Frage schien André François-Poncet nur ein »politisches Spiel ${ }^{137}$. Dem müsse die französische Außenpolitik Rechnung tragen, die nicht aus einem Guß sein könne. »Il faut faire des sacrifices à la naïveté des peuples, mais, parallèlement, il faut s'armer, et s'attendre aux aventures les plus dangereuses ${ }^{138}$. Denn die in »Mein Kampf « niedergelegte »doctrine fondamentale « (der Nationalsozialisten und damit der deutschen Außenpolitik) stelle die Franzosen als Haupthindernis der Expansion des »Germanismus « dar. »Il n'est pas impossible que cette thèse soit remise en honneur et que l'Allemagne se tourne tout d'abord vers la France, fidèle à la théorie, conformément à la phrase de Mein Kampf: celui qui a cassé les reins de la France est le maître de l'Europe ${ }^{139}$. André François-Poncet wollte also die Politik der Verhandlungen aus innenpolitischem Kalkül fortsetzen und sie mit einer Politik der Aufrüstung ergänzen, um gegen alle Eventualitäten gewappnet zu sein. Denn bei dem französischen Botschafter herrschte nach wie vor Unsicherheit über die Absichten der deutschen Politik:

M. Hitler veut-il sincèrement amener une détente? Est-il disposé à des concessions pour rétablir une atmosphère de paix à la faveur de laquelle il pourra digérer son récent coup de force? Sera-t-il sensible, au contraire, aux conseils de ceux de ses lieutenants qui le poussent à battre le fer pendant qu'il est chaud, à profiter des divisions de l'Europe et de l'inertie anglaise? Se laissera-t-il entraîner par les audacieux qui voudraient précipiter les choses et renouveler, à brève échéance, contre la Tchécoslovaquie ou l'Autriche la méthode du fait accompli? ${ }^{140}$.

${ }^{137}$ Ibid. S. 40.

138 Ibid.

${ }^{139}$ Ibid. S. 30.

${ }^{140}$ Depesche Nr. 657 vom 15. April 1936 (Botschafter François-Poncet an Außenminister Flandin), in: DDF II/2, Nr. 78, S. 129-134, hier S. 131. 
André François-Poncet wußte keine Antwort, vermutete aber, wie immer in unübersichtlichen Situationen, daß »deux courants, celui des exaltés et celui des modérés « um die Vorherrschaft kämpften. Sicher war der Botschafter dagegen, daß Deutschland eine britisch-französische Entente am meisten fürchte. „C'est parce que cette entente n'existait pas que $M$. Hitler a fait le coup de 7 mars. C'est parce que la dernière session de Genève a révélé de profondes divergences entre Français et Anglais que les Allemands croient leurs affaires en bonne voie $\ll$. Gleichzeitig erwarteten die Deutschen, daß der Abessinienkonflikt den Graben zwischen den Westmächten, d. h. Frankreich einerseits und Italien und Großbritannien andererseits, vertiefen werde. »Quelle que soit la solution à laquelle se ralliera la France, prise entre l'Angleterre et l'Italie, il ne pourra en résulter pour eux, espèrent-ils, que des avantages. Ou bien la France se rapprochera de l'Angleterre, ce qui, dans les circonstances actuelles, l'obligerait aussi à s'entendre avec l'Allemagne, ou bien elle se rapprochera de l'Italie, mais dans ce cas, elle se brouillera avec l'Angleterre ${ }^{141}$. Das war das Dilemma der französischen Außenpolitik, das nur auf einem paradoxen Weg zu lösen war: Die »amitié anglaise et l'alliance italienne $\ll \mathrm{zu}$ versöhnen und die Feindschaft zwischen den beiden LocarnoGarantiemächten zu beenden. »Les dirigeants du Troisième Reich l'écartent de leur esprit comme un cauchemar. Rien ne pourrait, en effet, leur être plus désagréable que la reconstitution du front de Stresa ${ }^{142}$. André FrançoisPoncet plädierte also, wie gesagt, für eine Doppelstrategie: internationale Organisation gegen Deutschland und bi- gegebenenfalls auch multilaterale Verhandlungen mit Deutschland.

Die Reichsregierung versuchte indes die Strategie mit einer Verzögerungstaktik zu durchkreuzen ${ }^{143}$. Sie nutze die westlichen Gesprächsangebote zum Taktieren, da die internationale Entwicklung die Reichsregierung nicht zur Eile drängte ${ }^{144}$. André François-Poncet bezweifelte, daß sich Deutschland mit Italien verbinden wolle. Trotz der »Verwandtschaft« der Regime pflege Deutschland im Grunde Mißtrauen und Mißachtung gegenüber dem unzuverlässigen Partner. Außerdem bleibe das österreichische Problem ein schwierig zu überwindendes Hindernis. ${ }^{145}$ Auch die Petite Entente und die Entente balkanique hielten unter französischer Führung stärker zusammen, als Deutschland das erwartet habe. Die baltischen Staaten zeigten ebenfalls den

\footnotetext{
${ }^{141}$ Ibid. S. 134.

142 Ibid.

${ }^{143}$ Telegramm Nr. 1510 vom 21. Mai 1936, in: DDF IV/2, Nr. 228, S. 351f., hier S. 352.

144 Telegramme Nr. 1387-1390 vom 10. Mai 1936, in: DDF II/2, Nr. 194, S. 294f., hier S. 295. Zum Zusammenhang siehe HILDEBRAND, Vergangenes Reich, S. 714f.

${ }^{145}$ Depesche Nr. 815 (Botschafter François-Poncet an Außenminister Flandin) vom 13. Mai 1936, S. 11, in: CADN, Ambassade Berlin, Série B, Carton 205.
} 
Wunsch, sich stärker gegen jede Gefahr zusammenzuschließen. Der Zerfall Österreichs und der Tschechoslowakei habe ebenfalls noch nicht die in Berlin gewünschte Reife erreicht ${ }^{146}$. Vor diesem Hintergrund hielt André FrançoisPoncet eine kriegerische Auseinandersetzung für unwahrscheinlich ${ }^{147}$. Außerdem dächten die Nationalsozialisten an die Olympischen Sommerspiele, die ihnen nicht nur einen Einfluß- und Prestigezuwachs brächten, sondern auch Devisen.

Aus diesen Gründen schien dem Botschafter, daß Deutschland Abenteuer zumindest bis in den Herbst 1936 - vermeiden wolle. Zwar habe Hitler seine kühnen Pläne und seine Träume von einem neuen germanischen Reich nicht aufgegeben, aber Opportunitätsgründe dürften ihn - zumindest vorläufig - zu einer vorsichtigen und friedlichen Haltung bewegen, auf die man sich angesichts des Charakters des Reichskanzlers - aber nicht zu sehr verlassen dürfe... Insofern erschienen dem Botschafter im Sommer 1936 die deutschen Absichten kaum erkennbar ${ }^{148}$. Grundsätzlich seien aber die Ziele der deutschen Außenpolitik gleich geblieben: »Elle cherche à éloigner l'Angleterre de la France, à capter la Grande-Bretagne, pour s'assurer sa neutralité, sinon son amitié, à se concilier l'Italie, pour éviter un retour à la formation de Stresa. Elle s'applique à disloquer la Petite Entente, pour frayer les voies à son hégémonie en Europe centrale ${ }^{149}$. Diese Ziele strebe Deutschland zur Not auch auf dem Verhandlungswege oder über den Umweg über Genf an ${ }^{150}$. Vor diesem Hintergrund werde die deutsche Antwort auf den britischen Fragebogen, so die Einschätzung des Botschafters, in erster Linie taktischen Überlegungen folgen, ohne daß der Grund ihrer Taktik verändert werden würde ${ }^{151}$. Deutschlands Revisionswillen sei klar und deutlich. Deshalb werde auch Deutschland kaum in einen Völkerbund zurückkehren. "Pour qu'elle s'y résolût, il faudrait qu'elle vît qu'elle a affaire à des gens décidés, prêts à s'entendre entre eux et à constituer, sans elle, voire contre elle, un front solide. Dans ce dernier cas, les États garants du maintien de la paix devraient encore se sentir sur leurs gardes pour éviter que le Reich, n'ayant pu dissocier, du dehors le bloc qu'ils constituent, ne s'efforce de le faire sauter du dedans ${ }^{152}$. André François-Poncet glaubte also Deutschland nur mit einer Koalition im Zaum halten bzw. einspannen zu können. Die nationalsozialistische Führung

\footnotetext{
146 Ibid. S. $12 \mathrm{f}$.

${ }^{147}$ Ibid. S. 13.

${ }^{148}$ Depesche Nr. 1007 vom 18. Juni 1936 (Botschafter François-Poncet an Außenminister Delbos), in: DDF IL/2, Nr. 317, S. 478-482, hier S. 478.

149 Ibid. S. 481.

${ }^{150}$ Ibid. S. 481 .

${ }^{151}$ Depesche Nr. 1099 vom 2. Juli 1936 (Botschafter François-Poncet an Außenminister Delbos), S. 17, in: CADN, Ambassade Berlin, Série B, Carton 206.

${ }^{152}$ Ibid. S. $18 \mathrm{f}$.
} 
betrachte eine französisch-britische Entente als ein Hindernis für ihre Pläne. Infolgedessen sei sie »un facteur essentiel de la paix ${ }^{153}$. Vor diesem Hintergrund plädierte André François-Poncet für die Übernahme der diplomatischen Initiative:

Le moment parait venu de renverser les rôles, de pousser l'Allemagne dans ses retranchements et de l'amener à répondre par oui ou par non à des invitations précises. S'il est vrai qu'elle ne veuille point contribuer à clarifier la situation parce qu'elle garde le secret espoir de faire en eau trouble des pêches plus fructueuses, il ne peut qu'y avoir avantage à l'obliger à étaler en plein jour sa mauvaise volonté ${ }^{154}$.

Der Wunsch des Botschafters schien Gehör zu finden. Die seit Anfang Juli geplante 5-Mächte-Konferenz in Brüssel führte zu einer Demarche der Locarno-Mächte, die Deutschland zur Teilnahme an den Verhandlungen einluden ${ }^{155}$. Die Reichsregierung nahm - im Hinblick auf die Olympischen Sommerspiele - die Einladung Ende Juli an ${ }^{156}$. Daß Hitler und seine Mitarbeiter einen Erfolg der bevorstehenden Konferenz wünschten, war für André François-Poncet eine Frage, über die man sich keine Illusionen machen sollte ${ }^{157}$. Insofern blickte der Botschafter nicht optimistisch in die Zukunft der deutsch-französischen Beziehungen.

L'expérience de ces demières années a malheureusement prouvé, en effet, qu'en Allemagne, l'amabilité, la flatterie, la bonne volonté ne sont séparées que par une cloison très fragile de l'antipathie et de la menace. En un clin d'cil, l'horizon se transforme et, presque sans transition, passe de la sérénité à l'orage. Il en était déjà de même avant la guerre. En 1912 et en 1913, Guillaume II faisait, lui aussi, altemer le compliment et l'invective, la caresse et l'injure. Tantôt, il nous présentait le gant de velours, tantôt la main de fer. Les procédés du III $^{\mathrm{e}}$ Reich sont calqués sur ceux du II ${ }^{\mathrm{e}}$. Entre le Kaiser et M. Hitler, il n'y a pas, sur bien des points, une différence de nature, il y a, tout au plus, une différence de degré $e^{158}$.

Angesichts dieser pessimistischen Prognose setzte André François-Poncet in jeden Ansatz die Hoffnung, das Unabwendbare abwenden zu können. Der Paris-Besuch des Reichsbankpräsidenten Schacht Ende August 1936 hätte ein Ausgangspunkt sein können. Der sei nämlich überzeugt, daß sich Europa in einer schweren Krise befinde: Der Rüstungswettlauf ruiniere den Kontinent und ziehe ihn in eine "conflagration épouvantable ${ }^{159}$. Vor diesem Hinter-

153 Ibid. S. 19.

154 Ibid. S. 20.

${ }^{155}$ Telegramme Nr. 2273-2277 vom 24. Juli 1936, in: DDF III/2, Nr. 23, S. 50f. sowie Telegramme Nr. 2292-2297 vom 25. Juli 1936, in: DDF III/2, Nr. 29, S. 57f. Zum Kontext siehe DUROSELLE, Histoire diplomatique, S. $201 \mathrm{f}$.

156 Telegramme Nr. 2371-2372 vom 1. August 1936, in: DDF III/2, Nr. 55, S. 97. Siehe auch Depesche Nr. 1246 vom 5. August 1936 (Botschafter François-Poncet an Außenminister Delbos), in: DDF IIV/, Nr. 88, S. 134-139, hier S. 134.

157 Ibid. S. 135.

${ }^{158}$ Ibid. S. 137.

159 Telegramme Nr. 2687-2690 vom 24. August 1936, in: DDF III/2, Nr. 196, S. 275. 
grund müsse der Gedanke einer freiwilligen Rüstungsbeschränkung wieder aufgenommen werden, neue Wirtschaftsabkommen geschlossen und eine Währungsabwertung beschlossen werden. In diese Richtung sei auch Hitler zu bewegen. Überlegungen, die bei André François-Poncet auf offene Ohren gestoßen sein dürften. Schließlich hatte der Botschafter seinerzeit ebenfalls Rüstungsbeschränkungen bzw. Wirtschaftsabkommen gefordert. Insofern beeilte er sich, Schacht zu versichern, daß er, Schacht, großes Verständnis in Paris finden werde und da $B$ die französischen Vorstellungen in eine entsprechende Richtung gingen ${ }^{160}$.

Während der Reichsbankpräsident in Paris weilte, stimmte Berlin nicht nur der französischen Nicht-Einmischungserklärung für Spanien zu, sondern verlängerte auch die Wehrpflicht auf zwei Jahre. Dieser Schritt bewies für André François-Poncet, daß Hitler kaum an den Frieden glaube. "C'est une nouvelle application de la méthode déjà employée et qui consiste à combiner un geste de guerre avec une parole de paix, afin de compenser l'un par l'autre et de troubler l'opinion étrangère ${ }^{161}$. Gleichwohl entwerte sie in den Augen des Botschafters die Schacht-Reise nicht. André François-Poncet führte die Entscheidung vom 24. August auf den wachsenden Einfluß der Generale auf Hitler zurück ${ }^{162}$. Infolge dieser Einschätzung revidierte der Botschafter sein positives Bild von der militärischen Führung Deutschlands, als bis dato mäßigendes und friedensstiftendes Element galt.

Mais on doit se demander aujourd'hui s'ils ne cèdent pas à la tentation de refaire l'expérience de 1914 et de recommencer l'entreprise qu'ils ont manquée à cette époque. En tout cas, la hantise du spectre rouge, à laquelle M. Hitler est si sensible, leur fournit le moyen d'obtenir du Führer tout ce qu'ils désirent. Et il est déjà visible que le mot d'ordre antibolchéviste leur sert, non seulement à mettre sur pied une armée beaucoup plus forte que celle que le Reich possédait en 1914, mais encore à essayer d'organiser autour de l'Allemagne et de la Hongrie un bloc militaire des puissances centrales ${ }^{163}$.

André François-Poncet glaubte also wieder und immer noch, im Reichskanzler den Getriebenen zu sehen, der - so die Analyse des Botschafters - gleichwohl die Entscheidungen nach seinem Gutdünken fälle.

Il [Hitler, cws] médite longuement; il tranche subitement. Lorsqu'il a une idée en tête, il la laisse lentement prendre forme; il en pèse avec soin les avantages et les inconvénients; il la

${ }^{160}$ Ibid. Der Reichsbankpräsident sprach am 28. August mit dem französischen Ministerpräsidenten, vgl. Compte Rendu, in: DDF III/2, Nr. 213, S. 307-311.

161 Telegramme Nr. 2698-2703 vom 25. August 1936, in: DDF II/2, Nr. 198, S. 277f., hier S. 278. Die Effektivstärke der Reichswehr erhöhte sich - nach Berechnung des Botschafters - auf 700000 Mann, vgl. Telegramme Nr. 2706-2710 vom 25. August 1936, in: DDF IIV/2, Nr. 200, S. 280 f.

${ }^{162}$ Telegramme Nr. 2723-2727 vom 26. August 1936, in: DDF III/2, Nr. 204, S. 285f., hier S. 286.

${ }^{163}$ Ibid. 
garde comme un secret précieux; tout au plus en fait-il confidence à de rares intimes avec lesquels il la discute, mais qui ignorent le plus souvent si elle verra le jour ou non. Puis, tout à coup, il s'allume, dans le cerveau du Führer, une étincelle; la décision explose alors et elle intervient avec la rapidité de l'éclair ${ }^{164}$.

So sei der Reichskanzler am 30. Juni 1934, am 15. März 1935, am 7. März 1936 und am 24. August vorgegangen. Diese Vorgehensweise berge die Gefahr plötzlicher Initiativen und Offensiven, die keine Indizien und Indiskretionen ankündigen würden ${ }^{165}$. Das sei eine der Lehren des 24. August. Sie führten aber André François-Poncet nicht zu dem naheliegenden SchluB, seinen Botschafterposten aufzugeben. Wenn seine Funktion in der Vermittlung der französischen Außenpolitik und in der Ermittlung der deutschen bestand, dann konnte er nach dieser Feststellung unter der gegebenen Regierung nur den ersten Teil - und das auch nur bedingt - seiner Aufgabe erfüllen.

$\mathrm{Da} \beta$ André François-Poncet trotzdem auf seinem Posten blieb, hatte einen biographischen Grund. Der Botschafter fürchtete den Ausbruch eines europäischen Krieges, den er zu verhindern helfen wollte. Noch sei die Entwicklung nicht unaufhaltbar ${ }^{166}$. Die Hitler-Regierung müsse, bis zu einem gewissen Grad, auch der nicht gerade kriegsbegeisterten Stimmung in der Bevölkerung Rechnung tragen. Außerdem seien in Deutschland einige Männer über den Gang der Dinge so besorgt, daß sie sie in eine andere Richtung lenken wollten. André François-Poncet zählte Reichsbankpräsident Schacht zu diesen Männern, deren Bemühungen er Erfolg wünschte. Die Konferenz von Brüssel werde das zeigen. "Si elle a lieu, si les représentants du gouvernement hitlérien s'y rendent, non pour la saboter, mais pour la conduire au succès, si les discussions politiques se terminent par la conclusion d'un nouveau pacte de Locarno qui facilitera la réalisation d'ententes économiques, on sera en droit de garder quelque espoir pour l'avenir “ ${ }^{167}$. Die für den Herbst vorgesehene 5Mächte-Konferenz in Brüssel erschien dem französischen Botschafter als letzte Chance, der internationalen Politik eine andere Richtung $\mathrm{zu}$ geben. Wenn Deutschland aber die Konferenz scheitern lasse, dann besteht kein Zweifel mehr: Adolf Hitler wolle in ein bis zwei Jahren Krieg führen. Frankreich und die friedliebenden Ländern müßten dann die Verantwortung des Reiches dafür unterstreichen, sich bewaffnen und für diesen Kampf vorberei$\operatorname{ten}^{168}$.

Angesichts der der Konferenz von Brüssel zugeschriebenen Bedeutung entwickelte André François-Poncet ein Verhandlungsschema, das er Ende Sep-

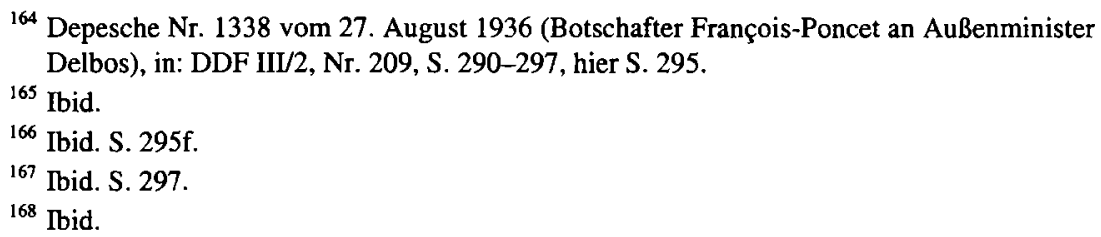


tember dem französischen Außenminister vorlegte ${ }^{169}$. André François-Poncet betrachtete »le projet d'un pacte de non-aggression et d'assistance mutuelle contre l'agresseur, avec clause d'arbitrage et de conciliation« ohne größere Schwierigkeiten realisierbar ${ }^{170}$. Gleichwohl sah der Botschafter das Problem der Vereinbarkeiten des neuen Locarnos mit dem französisch-polnischen, französisch-tschechischen und dem französisch-sowjetischen Vertrag voraus. Deutschland werde sich mit ersterem, aber nicht mit letzterem abfinden. Der deutsch-polnische Vertrag sowie ein gegen Zugeständnisse für die Sudeten zu erreichender deutsch-tschechischer Vertrag bildeten ausreichende Gegengewichte. Ein entsprechendes Abkommen zwischen Deutschland und der Sowjetunion hielt der Botschafter aber für ausgeschlossen, gleichwohl müsse der französisch-sowjetische Vertrag nicht aufgelöst werden. Das hätten weder Hitler noch Schacht noch die Wilhelmstraße gefordert. Infolgedessen glaubte André François-Poncet, daß sich das Reich mit bestimmten Präzisierungen und Garantien zufriedengeben werde. Mit der Versicherung, daß keine Militärkonvention bestehe, und dem Hinweis auf ein Einmischungsverbot hoffte André François-Poncet das Problem der Vereinbarkeit des zukünftigen Vertrags von Locarno mit den bestehenden Verträgen zu lösen und die Natur der Beziehungen zwischen Frankreich und der UdSSR klarzustellen. Anschließend könnten die Locarno-Mächte Deutschland um Klarstellung seiner Absichten gegenüber Sowjetrußland und entsprechende Garantien bitten.

Die antibolschewistische Propagandakampagne im Reich und die auf dem Reichsparteitag in Nürnberg gehaltenen Reden nährten den Verdacht, daß das Reich gegen die UdSSR Eroberungsabsichten hegt, die sich nur auf Kosten eines allgemeinen Krieges realisieren ließen. Wenn Deutschland, wie immer wieder behauptet, den Frieden wolle, dann müsse sie ihm Opfer bringen. Hitler sei zwar nicht bereit, direkte Verträge mit Rußland abzuschließen, aber indirekte Verpflichtungen mit Litauen, Polen und der Tschechoslowakei einzugehen. Nach Ansicht des Botschafters sollte auch die Frage der Rüstungsbeschränkung angesprochen werden, ohne auf eine sofortige Lösung zu hoffen. "Politiquement et psychologiquement, il serait déjà fort précieux d'arriver à dégager quelques lignes simples et d'obtenir quelques résultats modestes ${ }^{171}$. Die Rückkehr des Reiches in den Völkerbund wollte André François-Poncet mit den Eigeninteressen Deutschlands begriinden und bewerkstelligen. Deutschland übe innerhalb des Völkerbundes mehr Einfluß aus und damit auch auf den französisch-sowjetischen und den neuen LocarnoVertrag. Außerdem sei die Rückkehr für die westlichen Mächte die Voraussetzung, die Vergangenheit zu vergessen und in die Zukunft zu blicken. Vor

${ }^{169}$ Siehe Anhang, Dokument Nr. 7: Note pour le ministre, S. 343-347.

170 Ibid.

${ }^{171}$ Ibid. 
allem biete die Rückkehr die Möglichkeit, das Kolonialproblem zu lösen, auf das unten im Zusammenhang einzugehen sein wird. Wenn die politischen Verhandlungen $\mathrm{zu}$ einem guten Ende führten, könnten Wirtschafts- und Währungsabmachungen vorbereitet werden. Der Botschafter betonte, daß das Ergebnis der Brüsseler Konferenz in erster Linie von Berlin abhänge.

Diese Überzeugung war ein weiterer Grund, warum André François-Poncet auf seinem Posten in Berlin blieb und versuchte, auf der Grundlage der oben skizzierten Positionen auf die Außenpolitik des Reiches einzuwirken ${ }^{172}$. Diese Versuche wurden indes vom französischen Außenministerium gebremst. René Massigli, inzwischen Chef der Direction des Affaires politiques et commerciales am Quai d'Orsay schrieb seinem »cher ami«, daß er ihn mit »un peu d'inquiétude " mit Reichsaußenminister von Neurath über die Frage der Rüstungsbeschränkung habe sprechen sehen ${ }^{173}$. Diese könne »utilement« erst in der zweiten Verhandlungsphase angesprochen werden. Außerdem fürchte er, daß eine frühzeitige Diskussion der Rüstungsfrage Frankreich im Gegensatz nicht nur zu Deutschland, sondern auch zu Großbritannien bringen werde. Dementsprechend erwähne das französische Memorandum das Thema mit keinem Wort ${ }^{174}$. André François-Poncet reagierte verärgert auf diese Kritik aus Paris. Sein Gespräch mit von Neurath habe nur »un caractère d'explication« gehabt, seine Bemerkung zu einem möglichen Stop des Rüstungswettlaufes "n'était rien de plus qu'un sondage, une suggestion vague «, von der keine Schäden zu befürchten seien. Im übrigen habe er vor seiner Abreise mit Außenminister Delbos darüber gesprochen, der zugestimmt habe. "Il est vrai«, stimmte André François-Poncet den Einwänden Massiglis zu, »qu'il faut dévier les questions et avancer prudemment mais n'oublie pas non plus que nous n'obtiendrons de concessions dans un domaine qu'en fonction des satisfactions que les Allemands croiront pouvoir recueillir dans d'autres ${ }^{175}$. Der Botschafter erinnerte an die Methoden des Kuhhandels, die er - wie gesehen - schon Mitte der 20er Jahre als Charakteristikum der deutschen Politik beschrieben hatte. »À cet égard, il faudra évoquer les grandes lignes d'un règlement général et faire miroiter les avantages qui naîtraient d'un vaste accord d'ensemble, à plusieurs compartiments « ${ }^{176}$. André

${ }^{172}$ Vgl. seine Gespräche mit Außenstaatssekretär Dieckhoff am 9. Oktober, Telegramme Nr. 3186-3190 vom 9. Oktober 1936, in: DDF III/2, Nr. 328, S. 489f. und mit Reichsaußenminister von Neurath am 13. Oktober, Telegramme Nr. 3236-3247 vom 13. Oktober 1936, in: DDF III/2, Nr. 342, S. 508-510.

${ }^{173}$ Siehe das Schreiben vom 15. Oktober 1936, [S. 1], in: CADN, Ambassade Berlin, Série B, Carton 683 .

174 Ibid. [S. 4f.].

${ }^{175}$ Schreiben André François-Poncets an René Massigli vom 16. Oktober 1936, in: AMAE/PA-AP, Massigli, Vol. 97, S. 203r-203v.

176 Ibid. S. 203v. 
François-Poncet warf dem Freund vor, daß er sich »sur un plan qui n'est pas celui du possible et du réel« bewege. Theoretisch habe er ohne Zweifel recht.

Mais l'époque actuelle se moque des théories. Elle réclame des formules simples et directes, qui frapperont l'imagination et le cœur. Elle est lasse de l'esprit juridique, de ses précisions, de ses précautions, de ses distinctions byzantines. Le débat qui s'ouvre aurait besoin d'un renouvellement. On n'en viendra pas à bout avec le vieil attirail genevois, qui a déjà échoué ${ }^{177}$.

Sobald die Deutschen von Kontrolle u. ä. hörten, wollten sie nichts mehr hören und sehen. Sie würden vor der Aussicht auf die Arbeiten der alten Abrüstungskommission flüchten. »Il faudrait trouver«, forderte André François-Poncet, »je ne sais quoi d'autre, aborder par une autre face la question, inventer... avec le souci de répondre à l'attente de l'opinion publique et de dissiper le cauchemar qui pèse sur elle ${ }^{178}$. Das war das Ziel seiner »timides tentatives «, die der Botschafter, ziemlich beleidigt über die Kontrolle seiner Aktivitäten, einzustellen ankündigte ${ }^{179}$.

Tatsächlich führte André François-Poncet nach dieser Zurechtweisung aus Paris keine Gespräche mehr mit den Verantwortlichen in Berlin über ein neues Locarno, die Rückkehr Deutschlands nach Genf usw. Der Meinungsaustausch wurde über einen Notenaustausch weiter verfolgt, der sich über Monate zwischen London, Paris, Berlin und Brüssel hinschleppte ${ }^{180}$. Die Verzögerung ging vor allem auf das Konto Deutschlands, das, so die Einschätzung des Botschafters, Zeit gewinnen wolle. Deutschland erwarte Veränderungen in der Welt, die seiner Politik in die Hände spielen würden. Diese Strategie verfolge die Reichsregierung seit dem Ausbruch des Spanischen Bürgerkrieges im Sommer 1936, der als Katalysator zu einer schnelleren und tiefgreifenderen Neuordnung der internationalen Beziehungen beitragen sollte ${ }^{181}$. Diese Entwicklung ist an dieser Stelle und bei der aufgeworfenen Fragestellung nur insoweit nachzuzeichnen, wie sie die deutschlandpolitischen Vorstellungen André François-Poncets beeinflußte. Er hielt es erneut für möglich, »que l'Allemagne prépare des initiatives ultérieures«, für die es eine Rechfertigung

${ }^{177}$ Ibid. S. 204r.

178 Ibid.

${ }^{179}$ Ibid. S. 204v.

${ }^{180}$ Deutsches Angebot Ende März, französische Antwort Anfang April, britischer Fragebogen im Mai, deutsche Antwort am 12. Oktober 1936 (DDF III/2, Nr. 337), britische Noten vom 4. und 19. November 1936 (DDF III/2, Nr. 439 und 513), französisches Memorandum vom 19. Dezember 1936 (DDF IV/2, Nr. 178) und belgisches Aide-mémoire vom 12. Februar 1937 (DDF IV/2, Nr. 432), deutsche Antwort vom 10. März 1937 (Telegramm Nr. 1084 vom 12. März 1936, in: DDF V/2, Nr. 98, S. 155), französisches Memorandum vom 9. Juni 1937, in: DDF VI/2, Nr. 49, S. 73-77.

181 Zum Spanischen Bürgerkrieg im allgemeinen siehe DUROSELLE, Histoire diplomatique, S. $197 \mathrm{ff}$. und S. 205ff. Zur französischen Politik vgl. DUROSELlE, Décadence, S. $301 \mathrm{ff}$. und zur deutschen siehe HILDEBRAND, Vergangenes Reich, S. $728 \mathrm{ff}$. 
suche $^{182}$. Der Außenminister versicherte ihm zwar, daß Deutschland eine »absolute Neutralität« wahren möchte, eine Versicherung, die er aber nicht ohne weiteres gab und die nach Einschätzung des Botschafters nicht unbedingt von Hitler, Goebbels und von Ribbentrop geteilt werden müsse ${ }^{183}$.

Vor diesem Hintergrund warnte er das französische Außenministerium vor der deutschen Haltung. "En réalité, nous avons toujours à faire à une Allemagne qui joue un jeu très serré, qui veut se donner les gants d'avoir témoigné d'un esprit pacifique pour que, si les choses tournent mal ou avortent, les torts ne puissent pas lui être imputés “ ${ }^{184}$. Vor diesem Hintergrund blieben bei dem Botschafter Zweifel, welche Politik die Reichsregierung gegenüber Spanien verfolgen werde ${ }^{185}$. Die erwartete Zustimmung des Reiches zur Nichteinmischung konnte André François-Poncet nicht beruhigen ${ }^{186}$. Der Botschafter fürchtete, daß Deutschland bei Gelegenheit seine neutrale Haltung aufgeben und versuchen werde, Kapital aus dem Spanischen Bürgerkrieg zu schlagen ${ }^{187}$. Die deutsche Antwort auf den französischbritischen Vorschlag vom 5. Dezember 1936 konnte in seinen Augen den Zweifel nicht vertreiben. André François-Poncet unterstellte der Reichsregierung Hintergedanken. Die Zustimmung sei nur ein Manöver, das den Wunsch nach einer Verlängerung der Auseinandersetzung verdecke. Die Zwischenfälle mit den sich an der Seeüberwachung Spaniens beteiligenden Booten »Deutschland« bzw. »Leipzig« schienen dem Botschafter in dieser Hinsicht sehr »instructif $«$ zu sein ${ }^{188}$.

Entscheidend für den französischen Botschafter in Berlin waren aber weder die internationalen Verhandlungen über die Nichteinmischung in Spanien noch die aus der internationalen Überwachung resultierenden Zwischenfälle und Komplikationen auf der iberischen Halbinsel, sondern die Polarisierungskräfte, die der Spanische Bürgerkrieg entwickelte. Sie förderten genau die bündnispolitische Umgruppierung, die der französische Botschafter fürchtete. Wie gesehen, hatte der italienische Äthiopienkrieg eine vergleichbare Wir-

182 Telegramme Nr. 2347-2348 vom 30. Juli 1936, in: DDF III/2, Nr. 45, S. 79.

${ }^{183}$ Vgl. Depesche Nr. 1246 vom 5. August 1936 (Botschafter François-Poncet an AuBenminister Delbos), in: DDF IIV/2, Nr. 88, S. 135-139, hier S. 138 und Telegramm Nr. 2365 vom 31. Juli 1936, in: DDF III/2, Nr. 53, S. 94.

${ }^{184}$ Vgl. Depesche Nr. 1246 vom 5. August 1936 (Botschafter François-Poncet an Außenminister Delbos), in: DDF III/2, Nr. 88, S. 135-139, hier S. 138f.

${ }^{185}$ Siehe Depesche Nr. 1280 vom 13. August 1936 (Botschafter François-Poncet an Außenminister Delbos), in: DDF III/2, Nr. 140, S. 202-208.

${ }^{186}$ Depesche Nr. 1304 vom 19. August 1936 (Botschafter François-Poncet an Außenminister Delbos), in: DDF III/2, Nr. 175, S. 250-255, hier S. 255.

${ }^{187} \mathrm{Vgl}$. Note pour le Ministre vom 4. September 1936, in: CADN, Ambassade Berlin, Série B, Carton 683.

${ }^{188}$ Depesche Nr. 1067 vom 7. Juli 1937 (Botschafter François-Poncet an Außenminister Delbos), in: DDF VI/2, Nr. 201, S. 326-334, hier S. 334. 
kung: Rom entfernte sich von London und Paris und näherte sich Berlin an. Infolgedessen standen sich Deutschland und Italien einerseits und Frankreich und Großbritannien andererseits gegenüber. Diese ideologische Differenzierung wurde durch den Spanischen Bürgerkrieg so verstärkt, daß eine bündnispolitische Verfestigung erfolgte. André François-Poncet hatte die Annäherungstendenzen Italiens an Deutschland seit Ende 1935 bzw. Anfang 1936 aufmerksam notiert. Die italienischen Bemühungen wurden seit Mitte Mai 1936 verstärkt fortgesetzt, wie der Botschafter Anfang Juni nach Paris meldete $^{189}$. André François-Poncet vermutete, daß Mussolini die deutsche Karte spiele, um von Frankreich, Großbritannien und dem Völkerbund die erhofften Zugeständnisse zu bekommen ${ }^{190}$. Die Deutschen hätten aber - trotz des italienischen Werbens - noch immer Zweifel über die künftige Politik Mussolinis, so daß sie eine Entscheidung hinauszögerten. Die wurde durch die internationalen Verwicklungen um den Spanischen Bürgerkrieg so erleichtert, $\mathrm{da} ß$ eine »atmosphère de rapprochement et d'entente « nicht nur beim Besuch des italienischen Außenministers in Berlin im Herbst 1936 herrschte, sondern auch allgemein in die deutsch-italienischen Beziehungen einzog ${ }^{191}$. André François-Poncet vermutete, daß der Besuch wichtige Ergebnisse zeitigen werde, die der deutsche Botschafter in Rom, von Hassell, mit dem italienischen Ministerpräsidenten ausgehandelt habe. Angesichts des am 25. Oktober veröffentlichten Schlußkommuniqués schienen Deutschland und Italien eine Harmonisierung ihrer Politik vereinbart zu haben, wobei sie sich »une certaine liberté d'allure « vorbehalten hätten: »Tantôt l'Allemagne marchera de l'avant, tantôt elle se placera en retrait de l'Italie. Mais les deux pays se renseigneront, se consulteront et assureront le parallélisme de leurs actions ${ }^{192}$. André François-Poncet fürchtete, daß die deutsch-italienische Entente »un pas décisif vers la constitution du bloc des puissances centrales allant de la mer Baltique à la mer Adriatique « sei. »Peut-être l'Europe est-elle encore éloignée de l'aboutissement d'un pareil dessein. Peut-être arrivera-t-on à jeter un pont, comme il est souhaitable, entre les deux groupes de puissances dont l'opposition est en train de se cristalliser ${ }^{193}$. Schließlich dürften weder die zahlreichen Wendungen der italienischen Politik, noch der Wechsel zwischen $\mathrm{Zu}$ - und Abneigung in den Beziehungen zu Berlin vergessen werden. »Il est fort possible«, schloß der Botschafter hoffnungsvoll, »que les deux dictateurs se disputent de nouveau et se brouillent un jour sur le partage de la peau de

\footnotetext{
${ }^{189}$ Telegramm Nr. 1682 vom 6. Juni 1936, in: DDF II/2, Nr. 278, S. $435 f$.

${ }^{190}$ Telegramme Nr. 1829-1833 vom 20. Juni 1936, in: DDF II/2, Nr. 325, S. 494f.

${ }^{191}$ Vgl. Depesche Nr. 1576 vom 22. Oktober 1936 (Botschafter François-Poncet an Außenminister Delbos), in: DDF IIL/2, Nr. 395, S. 603-607.

${ }^{192}$ Telegramme Nr. 3396-3407 vom 26. Oktober 1936, in: DDF III/2, Nr. 408, S. 622-624.

${ }^{193}$ Ibid. S. 624.
} 
l'ours ${ }^{194}$. Insofern sei die deutsch-italienische Entente noch nicht "definitiv «" ${ }^{195}$.

Der keinen Monat später geschlossene Anti-Komintern-Pakt zwischen Japan und Deutschland komplettierte aber in den Augen des französischen Botschafters die globale Umgruppierung der Mächtekonstellation. »Il est clair«, kommentierte André François-Poncet den VertragsabschluB, »que la diplomatie allemande cherche à constituer, de l'Asie à l'Europe, un front continu antirusse. La politique que le Reich suit vis-à-vis du Japon est manifestement inspirée par ce grand dessein ${ }^{196}$. Insofern sei der Abschluß des sogenannten Anti-Komintern-Paktes nicht überraschend, entsprechende Gerüchte kursierten seit Januar 1936 in der Reichshauptstadt. Trotz der deutschen Versuche, die Sowjetunion vom Balkan bis zum Baltikum einzukreisen, diese Politik mit einer Entente mit London zu verbinden und sie gleichzeitig gegen Frankreich abzugrenzen, unterstellte der Botschafter Deutschland kurzfristig keine kriegerischen Absichten. »Affirmer, dès maintenant, que le Troisième Reich est décidé à la guerre et prépare une guerre, dans laquelle il compte qu'il aura la France en face de lui, serait, peut-être, s'avancer trop loin «" ${ }^{197}$. André FrançoisPoncet rechnete mit dem bevorstehenden Winter 1936/1937, dem Devisen-, Rohstoff- und Lagerungsmangel Deutschlands einerseits und seiner außenpolitischen Lage, die weniger stark sei als sie scheine, andererseits. »On peut donc s'abstenir de lui prêter des desseins immédiatement offensifs et belliqueux ${ }^{198}$. Allerdings herrsche keine Übereinstimmung zwischen den Gefühlen, die Deutschland vorgebe zu haben, und den Handlungen, die das Reich unternehme ${ }^{199}$. Daß das Reich sich gleichwohl Zurückhaltung auferlegte, schien André François-Poncet mit den mit dieser Politik im Jahre 1936 er-

194 Ibid.

195 Depesche Nr. 1594 vom 27. Oktober 1936 (Botschafter François-Poncet an Außenminister Delbos), in: DDF III/2, Nr. 413, S. 631-635, hier S. 634.

${ }^{196}$ Depesche Nr. 1710 vom 25. November 1936 (Botschafter François-Poncet an Außenminister Delbos), S. 8f., in: CADN, Ambassade Berlin, Série B, Carton 206. Eine ausführliche Analyse des deutsch-japanischen Vertrages lieferte der Botschafter eine Woche später nach, siehe Depesche Nr. 1768 vom 3. Dezember 1936 (Botschafter François-Poncet an Außenminister Delbos), in: DDF IV/2, Nr. 90, S. 133-141. Zum Hintergrund vgl. DUROSELLE, Histoire diplomatique, S. $208 \mathrm{f}$.

${ }^{197}$ Depesche Nr. 1710 vom 25. November 1936 (Botschafter François-Poncet an Außenminister Delbos), S. 18, in: CADN, Ambassade Berlin, Série B, Carton 206.

${ }^{198}$ Ibid.

${ }^{199}$ Ibid. Informationen, daß Hitler einen Krieg gegen RuBland provozieren und ihn in zwei Monaten mit einem Angriff gegen die Tschechoslowakei beginnen möchte, wies André François-Poncet nicht vollständig zurück, siehe Telegramm Nr. 3954 vom 3. Dezember 1936, in: DDF IV/2, Nr. 86, S. 124f. 
reichten Erfolgen ${ }^{200}$, aber auch mit den nach wie vor offenen Fragen zusammenzuhängen:

Qu'il s'agisse de l'affaire d'Espagne, du problème des relations franco-allemandes ou de la question plus générale de la pacification de l'Europe, il est douteux que le $\mathrm{III}^{\mathrm{e}}$ Reich ait, d'une façon définitive, arêté sa ligne de conduite; il continue plutôt à hésiter entre les partisans des solutions de conciliation et ceux qui estiment que, seuls les procédés comminatoires ou le recours à la force pourront assurer au Reich la place qui lui revient en Europe ${ }^{201}$.

Die Entscheidung schien dem Botschafter zugunsten der Verständigung zu fallen. Trotzdem hielt sich Reichskanzler Hitler in seiner Rede zum 30. Januar zurück $^{202}$. Die Erklärungen Hitlers schienen André François-Poncet nicht aus einem $\mathrm{Guß}$ und - mit Ausnahme Rußlands - wenig faßbar und entschieden ${ }^{203}$. Insofern sei die Rede »un discours d'attente $\aleph^{204}$. Diese Einschätzung bekam der französische Botschafter vom Reichsaußenminister bestätigt, der die deutsche Zurückhaltung mit dem Spanischen Bürgerkrieg, der innenpolitischen Situation in Frankreich, den Schwierigkeiten Rußlands und den bevorstehenden Veränderungen in Großbritannien begründete ${ }^{205}$.

Ainsi, les dirigeants du III $^{\mathrm{e}}$ Reich paraissent, en ce moment, désireux de marquer une pause et de laisser mûrir les événements. Mais ils désirent, en même temps, utiliser cet entracte à des fins précises; ils veulent provoquer une détente, alléger l'atmosphère, répandre l'impression que la paix n'est pas menacée, qu'en tous cas, elle ne l'est pas par l'Allemagne, car l'Allemagne repousse avec horreur, et de toutes ses forces, l'hypothèse d'une guerre européenne. Leur préoccupation majeure est, pour l'instant, de donner des gages de leurs intentions pacifiques ${ }^{206}$.

${ }^{200}$ Siehe die Bilanz des Jahres 1936 in der Depesche Nr. 1879 vom 31. Dezember 1936 (Botschafter François-Poncet an Außenminister Delbos), in: DDF IV/2, Nr. 233, S. 385395.

${ }^{201}$ Depesche Nr. 90 vom 21. Januar 1937 (Botschafter François-Poncet an Außenminister Delbos), in: DDF IV/2, Nr. 336, S. 577-583, hier S. 579.

${ }^{202}$ Vgl. Schulthess' Europäischer Geschichtskalender, 1937, S. 19-32. Siehe auch 11. Januar und die Blum-Rede vom 24. Januar, die in Deutschland positiv aufgenommen worden war, siehe Depesche Nr. 121 vom 27. Januar 1937 (Botschafter François-Poncet an Außenminister Delbos), in: CADN, Ambassade Berlin, Série B, Carton 207 und die Telegramme Nr. 451-459 vom 30. Januar 1937, in: DDF IV/2, Nr. 373, S. 643-645.

${ }^{203}$ Telegramme Nr. 465-477 vom 31. Januar 1937, in: DDF IV/2, Nr. 378, S. 657-659, hier S. 458.

${ }^{204}$ Depesche Nr. 141 vom 2. Februar 1937 (Botschafter François-Poncet an Außenminister Delbos), in: DDF IV/2, Nr. 386, S. 667-676, hier S. 675. Siehe auch André FrançoisPoncets Bericht über sein kurzes Gespräch mit Hitler beim Neujahrsempfang für das Diplomatische Korps in Berlin, siehe Telegramme Nr. 530-533 und Nr. 538-541 vom 4. Februar 1937, in: DDF IV/2, Nr. 394, S. 684-686.

${ }^{205}$ Depesche Nr. 222 vom 18. Februar 1937 (Botschafter François-Poncet an Außenminister Delbos), in: DDF IV/2, Nr. 465, S. 807-812, hier S. 807.

${ }^{206}$ Ibid. S. 809. 
Diese vorsichtige und abwartende Haltung der deutschen Politik schien sich in den nächsten Monaten nicht zu verändern. »Une telle modération «, schrieb der Botschafter Anfang April 1937 nach Paris, »frappe l'observateur étranger ${ }^{207}$. Warum diese ungewohnte Mäßigung, fragte sich André François-Poncet. Der Botschafter gab zwei Gründe an: Entweder zwängen die wirtschaftlichen Schwierigkeiten die Reichsführung zu der Haltung oder sie spiele mal wieder auf Zeit ${ }^{208}$. André François-Poncet meinte, daß die Reichsführung mit dem Spanischen Bürgerkrieg rechne, einer Lockerung der französisch-britischen Entente, einem finanziellen Ruin und einer Revolution in Paris sowie einer Auflösung der Sowjetunion. Ob die deutsche Politik von diesen Überlegungen oder von wirtschaftlichen Zwängen bestimmt werde, wollte der Botschafter nicht entscheiden ${ }^{209}$. Die nationalsozialistischen Führer müßten sich jedoch stark verändert haben, um plötzlich ehrliche Vorkämpfer für die europäische Stabilität zu sein. Die offensichtliche Zurückhaltung Deutschlands sei jedenfalls nicht ohne Hintergedanken ${ }^{210}$.

Wie die auch gewesen sein mögen, wenige Tage später versuchte Reichsaußenminister von Neurath den französischen Botschafter - offensichtlich mit Erfolg - von den deutschen Entspannungsbemühungen zu überzeugen ${ }^{211}$. Der Außenminister schien einen Politikwechsel, eine Annäherung an die westlichen Staaten, eine Rückkehr in den Kreis der Großmächte und zu den normalen Gewohnheiten zu wünschen. »En réalité, il ne fait pas de doute pour moi que le baron von Neurath, ainsi du reste, que $M$. Schacht, ne comprenne qu'un réarmement trop précipité, l'autarcie et le plan de quatre ans entraînent l'Allemagne vers des difficultés considérables ${ }^{212}$. Die sah André FrançoisPoncet vor allem auf wirtschaftlichem Gebiet. Aus diesem Grund schenkte er zu der Zeit auch Gerüchten Glauben, daß Deutschland die Einberufung einer Weltwirtschaftskonferenz wünsche ${ }^{213}$. Die Führer des Reiches fürchteten indes, ihren Wunsch mit genauen Forderungen der drei westlichen Großmächte beantwortet zu sehen. »Cette question des contreparties constitue«, schloß André François-Poncet, »la pierre de touche des intentions réelles de l'Allemagne ${ }^{214}$. André François-Poncet war sich nicht sicher, ob der »öko-

${ }^{207}$ Depesche Nr. 560 vom 8. April 1937 (Botschafter François-Poncet an Außenminister Delbos), in: DDF V/2, Nr. 233, S. 371-377.

${ }^{208}$ Ibid. S. 376.

${ }^{209}$ Ibid. S. 377.

${ }^{210}$ Ibid.

${ }^{211}$ Telegramme Nr. 1632-1637 und Nr. 1641-1647 vom 21. April 1937, in: DDF V/2, Nr. 311, S. $507 \mathrm{ff}$.

${ }^{212}$ Telegramm Nr. 1655 vom 22. April 1937, in: DDF V/2, Nr. 317, S. $517 f$.

${ }^{213}$ Vgl. Depesche Nr. 656 vom 22. April 1937 (Botschafter François-Poncet an Außenminister Delbos), in: DDF V/2, Nr. 325, S. 538-544.

${ }^{214}$ Ibid. S. 543. 
nomische Zwang " oder die "nationalen Ambitionen« stärker sein, ob die »Gemäßigten « über die »Fanatischen« siegen würden. In diesem Kampf hatten erstere seit der Machtergreifung nicht die Oberhand. Sie suchten erneut ihre Chance $^{215}$.

Die zweite Paris-Reise von Reichsbankchef Schacht brachte nicht die von André François-Poncet erhoffte Klärung, weil sich die deutsche Seite anschließend in Schweigen hüllte ${ }^{216}$. Zentraler Verhandlungspunkt in Paris war die deutsche Forderung nach Rückgabe der Kolonien, die Reichsbankpräsident Schacht seit langem vertrat und die Reichskanzler Hitler im Herbst 1936 auf dem Reichsparteitag in Nürnberg übernommen und - nach einer regierungsinternen Auseinandersetzung im Frühjahr $1937^{217}$ - auf dem Erntedankfest 1937 mit Nachdruck erneuert hatte. Die »marotte coloniale« der nationalsozialistischen Politik war nach Einschätzung des französischen Botschafters anfänglich nur von »taktischem Interesse« für die NSDAP ${ }^{218}$. Die Wilhelmstraße sehe allerdings in der Kolonialfrage »une monnaie d'échange«, die gegen Vorteile auf anderem Gebiet eingetauscht werden könne ${ }^{219}$. Vor dem Hintergrund der internationalen Probleme spielte dieses Politikfeld in den ersten Jahren der nationalsozialistischen Herrschaft abber eine untergeordnete Rolle $^{220}$. Erst im Laufe des Jahres 1935 glaubte der Botschafter die deutschen Kolonialforderungen hörbarer zu vernehmen ${ }^{221}$. »En 1934«, schrieb André François-Poncet in seinem Rückblick auf das Jahr 1935, "la politique allemande paraissait avoir oublié ses visées coloniales. En 1935, elle a ouverte-

${ }^{215}$ Ibid. S. 544. Siehe auch Telegramme Nr. $1725-1726$ vom 26. April 1937, in: DDF V/2, Nr. 344, S. 568f.

${ }^{216}$ Ende Mai, siehe DDF V/2, Nr. 470. André François-Poncet war über den Inhalt der Gespräche nicht informiert worden, vgl. Telegramme Nr. 2485-2493 vom 19. Juni 1937, in: DDF VI/2, Nr. 94, S. 155-157.

${ }^{217}$ Vgl. Telegramme Nr. 1097-1098 vom 13. März 1937, in: DDF V/2, Nr. 101, S. 163.

${ }^{218}$ Depesche Nr. 304 vom 30. März 1933 (Botschafter François-Poncet an Außenminister Paul-Boncour), in: DDF IIL/1, Nr. 70, S. 118-124, hier S. 122. Siehe dazu Klaus HILDEBRAND, Vom Reich zum Weltreich. Hitler, NSDAP und koloniale Frage 19191945, München 1969.

${ }^{219}$ Ibid. S. $122 f$.

${ }^{220}$ Vgl. Depesche Nr. 477 vom 4. April 1934 (Botschafter François-Poncet an Außenminister Barthou), in: CADN, Ambassade Berlin, Série B, Carton 196/2.

${ }^{221}$ Siehe Depesche Nr. 26 vom 9. Januar 1935 (Botschafter François-Poncet an Außenminister Laval), in: CADN, Ambassade Berlin, Série B, Carton 203; Depesche Nr. 1568 vom 30. Oktober 1935 (Botschafter François-Poncet an Ministerpräsident und Außenminister Laval), in: DDF XIII/1, Nr. 140, S. 193f. und Depesche Nr. 31 vom 8. Januar 1936 (Botschafter François-Poncet an Ministerpräsident und Außenminister Laval), in: CADN, Ambassade Berlin, Série B, Carton 205. 
ment réclamé la restitution de ses anciennes possessions d'outre-mer et étalé crûment ses ambitions révisionnistes «222.

Neben den bisher vorgebrachten ökonomischen Gründen traten nach Einschätzung des Botschafters immer mehr politische Überlegungen in den Vordergrund, die im Laufe des Jahres 1936 wiederholt - unter anderem von Reichsbankpräsident Schacht - vorgetragen wurden ${ }^{223}$. Der von Schacht vorgeschlagene Deal, Kolonien gegen (politische) Zugeständnisse und ein allgemeines Abkommen in Europa, schien dem Botschafter »assez équivoque«. Er müsse näher erklärt werden und könne erst ernst genommen und verhandelt werden, nachdem der Wortlaut vollkommen klar wäre ${ }^{224}$. Nach der Wiederbesetzung des Rheinlandes hatte die deutsche Kolonialforderung für André François-Poncet eine andere Form, einen anderen Charakter angenommen. Schließlich sei Deutschland nicht mehr verwundbar, könne das Versailler System nicht mehr so ohne weiteres aufrecht erhalten werden ${ }^{225}$. Insofern glaubte der französische Botschafter nicht mehr, daß über Rückgabeverhandlungen die deutsche Außen- und auch Wirtschaftspolitik beeinflußt werden könne ${ }^{226}$. Vor diesem Hintergrund hielt es der Botschafter für wichtig, die deutschen Absichten aus dem Dunkel zu ziehen und herauszufinden, ob sich Deutschland an einem »règlement général européen « beteiligen wolle ${ }^{227}$. André François-Poncet kehrte vor diesem Hintergrund zu alten Überlegungen zurück:

Si l'Allemagne accepte l'idée d'un règlement général, c'est qu'elle ne repousse pas a priori l'hypothèse d'un arrangement dans lequel, renonçant pour sa part à remettre en cause par violence les frontières de l'Autriche, de la Tchécoslovaquie et de la Russie, abandonnant tout établissement stratégique aux Baléares, se prêtant à un essai de limitation des armements, et à un retour à une Société des Nations, éventuellement modifiée, elle recevrait, d'autre part, sous une forme ou sous une autre, un domaine colonial et des concessions d'ordre économi-

${ }^{222}$ Depesche Nr. 211 vom 4. Feburar 1936 (Botschafter François-Poncet an Außenminister Flandin), in: DDF I/2, Nr. 133, S. 183-188, hier S. 188.

${ }^{223}$ Siehe das am 13. Oktober 1936 gegenüber dem französischen Botschafter dargelegte Wirtschaftsprogramm, in: Depesche Nr. 1522 vom 14. Oktober 1936 (Botschafter François-Poncet an Außenminister Delbos), in: DDF III/2, Nr. 354, S. 542f. sowie Telegramm Nr. 1460 vom 16. Dezember 1936, in: DDF IV/2, Nr. 159, S. 259.

${ }^{224}$ Depesche Nr. 1848 vom 21. Dezember 1936 (Botschafter François-Poncet an Außenminister Delbos), in: DDF IV/2, Nr. 187, S. 307-314, hier S. 311.

${ }^{225}$ Ibid. S. 314.

${ }^{226}$ Depesche Nr. 1580 vom 7. Oktober 1937 (Botschafter François-Poncet an Außenminister Delbos), in: DDF VII/2, Nr. 25, S. 63-67, hier S. 67. André François-Poncet führte die Schärfe der Forderung auf den Einfluß Mussolinis zurück, der wenige Tage vor der Rede in Deutschland zum Staatsbesuch war. Siehe die Bilanz des Mussolini-Besuches in Depesche Nr. 1587 vom 7. Oktober 1937, in: DDF VII/2, Nr. 38, S. 73-78.

${ }^{227}$ Telegramme Nr. 4532-4540 vom 15 . November 1937, in: DDF VII/2, Nr. 232, S. 425427, hier S. 426. 
que et financier. Dans ces conditions, une perspective de détente, d'entente et de pacification durable se présenterait aux regards ${ }^{228}$.

Der Botschafter wollte sich also (außen)politische Zugeständnisse Deutschlands erkaufen. Das - wie gesehen - schon im Sommer 1931 verfolgte Konzept schien dem Botschafter angesichts der wirtschaftlichen Schwierigkeiten des Reiches Aussicht auf Erfolg und Entspannung zu bieten. »Mais, si au contraire, elle rejette tout plan de ce genre, si elle refuse d'engager l'avenir et de se lier en quoi que ce soit, se bornant à répéter qu'elle souhaite la paix, sans dire quelle paix, on devra comprendre qu'elle va vers l'aventure, qu'elle préfère garder les mains libres et se réserve de profiter des occasions « ${ }^{229}$. Die aufgeworfene Frage schien die Reise Lord Halifax' im Herbst nicht beantwortet zu haben. »L'Allemagne n'a pas abattu son jeu; lord Halifax ne semble pas l'y avoir amenée; à peine en a-t-elle retourné une des cartes, la carte coloniale ${ }^{230}$. Diese Offenbarung führte zum Versuch eines $»$ colonial appeasement «, das im Frühjahr 1938 scheiterte.

Ein »alarmierendes Zeichen« war für André François-Poncet aber schon der Rücktritt Schachts Ende November 1937 gewesen $^{231}$. Gleichzeitig stellte der Botschafter fest, daß das Auswärtige Amt immer stärker unter den Einfluß der Nationalsozialisten gerate. »Loin de s'adoucir et de s'humaniser à mesure que son appareil militaire s'accroît et se perfectionne, le III $^{\mathfrak{e}}$ Reich se raidit, enfle la voix et augmente ses prétentions ${ }^{232}$. Die Reise Lord Halifax habe das ans Licht gebracht, der Rücktritt Schachts liefere einen weiteren Beleg. André François-Poncet führte diese Entwicklung auf die dem Reich innewohnende Dynamik zurïck, die das Regime einer Art Beschleunigungsgesetz unterwerfe. "Le III ${ }^{\mathrm{e}}$ Reich éprouve le besoin de se dépasser sans cesse et d'entretenir le fanatisme de ses partisans. Il subit le vertige du succès, l'enivrement du pouvoir qu'il exerce sur des millions d'hommes. La mégalomanie devient l'un des traits dominants de ses chefs, et principalement du Führer ${ }^{233}$. Die Chefs des $»$ Dritten Reiches $«$ verfolgten sicher einen $»$ souci de tactique $\ll^{234}$. Vor

228 Ibid.

229 Ibid.

${ }^{230}$ Telegramme Nr. $4728-4733$ vom 26 . November 1937 , in: DDF VII/2, Nr. 272, S. 484f., hier S. 484. André François-Poncet wurde zwar nach den deutsch-britischen Gesprächen von Lord Halifax empfangen, ohne daß dieser den französischen Botschafter über den Gegenstand der Gespräche ausführlich informierte, siehe die Telegramme Nr. 4633-4641 vom 21. November 1937, in: DDF VII/2, Nr. 258, S. 464f. und Telegramme Nr. 46494659 vom 22. November 1937, in: DDF II/2, Nr. 260, S. 467-469.

${ }^{231}$ Telegramme Nr. 4747-4756 vom 27. November 1937, in: DDF VII/2, Nr. 278, S. $498 f$.

${ }^{232}$ Vgl. Telegramme Nr. 4855-4858 vom 4. Dezember 1937, in: DDF VIU/2, Nr. 312, S. 602 f., hier S. 602 .

${ }^{233}$ Depesche Nr. 1907 vom 8. Dezember 1937 (Botschafter François-Poncet an InterimsAußenminister Chautemps), in: DDF VII/2, Nr. 324, S. 624-633, hier S. 628.

234 Ibid. 
diesem Hintergrund erwartete der Botschafter ein kritisches Jahr 1938, in dem er die von ihm befürwortete Doppelstrategie weiter zu verfolgen gedachte.

Aussi la meilleure politique à opposer au III $^{e}$ Reich semble-t-elle devoir consister à faire preuve, à l'égard de ses dirigeants et de son peuple, de modération, s'ils veulent être modérés, et d'énergie s'ils se montrent intransigeants et formulent des exigences déraisonnables; de leur démontrer que ni la France, ni l'Angleterre, ne sont aussi malades qu'ils le croient ou qu'on cherche à le leur faire croire; de les avertir, enfin, que, s'ils se laissaient guider par les aventuriers qui les poussent à la guerre, cette guerre ne serait ni courte, ni facile et grouperait, en face d'eux, une coalition analogue à celle de 1914, et contre laquelle, une fois de plus, l'Allemagne se briserait ${ }^{235}$.

Deutschland hatte nach Einschätzung des Botschafters den Rubikon überschritten $^{236}$. Fragte sich nur, in welche Richtung die Reise ging. André François-Poncet hatte sie schon mehrfach angedeutet: Österreich, Tschechoslowakei und der Balkan standen als nächstes auf der deutschen Rechnung ${ }^{237}$. Bevor Hitler diese begleichen lassen wollte, mußte er sich aber einiger Weggefährten entledigen, die ihm in den vergangenen Jahren zwar nützlich, in Zukunft aber hinderlich sein würden. Die Auswirkungen der Kaltstellung der Konservativen auf die deutschlandpolitischen Vorstellungen des Botschafters gilt es als nächstes zu untersuchen, bevor abschließend die letzten Revisionsschritte Hitlers und die deutschlandpolitische Reaktion des Botschafters darzustellen sind.

${ }^{235}$ Ibid. S. 633.

${ }^{236}$ Depesche Nr. 1930 vom 16. Dezember 1937 (Botschafter François-Poncet an InterimsAußenminister Chautemps), in: DDF VII/2, Nr. 361, S. 732-740, hier S. 734.

${ }^{237}$ Ibid. S. 739. 
